\title{
Angina-Like Chest Pain as a Symptom of Digestive Tract Disorders
}

\author{
Jacek Budzyński \\ ${ }^{1}$ University Chair of Gastroenterology, Vascular Diseases and Internal Medicine, \\ Nicolaus Copernicus University in Torun, Ludwik Rydygier \\ Collegium Medicum in Bydgoszcz \\ ${ }^{2}$ Clinical Ward of Vascular Diseases and Internal Medicine \\ Dr Jan Biziel University Hospital No. 2 in Bydgoszcz \\ Poland
}

\section{Introduction}

Chest pain is a common problem in health care, especially due to its prevalence, the utilization of resources according to the cost of medical procedures, and diagnostic process difficulties. Precordial discomfort occurs in 13-30\% of the adult population per year (Cayley, 2005; Dickman \& Fass, 2006; Eslick \& Talley, 2004; Eslick et al., 2005; Eslick, 2008; Fass, 2008; Fass \& Navarro-Rodriguez, 2008; Laird et al., 2004; Ruigómez et al., 2006, 2009), and in 20$40 \%$ population during their lifetime (Ruigómez et al., 2006, 2009). About $1.5-5 \%$ of the general population seeks a primary care doctor consultation because of chest pain episodes (Cayley, 2005; Erhardt et al, 2002; Eslick, 2008; Fox, 2005; Sheps et al., 2004). Moreover, it is the cause of 634,000 per year cardiologist consultations in the US (Mant et al., 2004), 5\% of visits to emergency departments in the UK, and $40 \%$ of non-surgical emergency admissions mainly due to acute coronary syndrome suspicion (Ruigómez et al., 2006). Among these patients, only in $15-40 \%$ was ischaemic heart disease (IHD) diagnosed on discharge and features of myocardial infarction presented in only 8-10\% (Dickman \& Fass, 2006; Liuzzo et al., 2005). The analysis by Hollander et al. (2007) has also shown that among patients admitted due to acute coronary syndrome suspicion, myocardial infarction was confirmed in only $4 \%$. Moreover, it has been known for a number of years that about $10-36 \%$ of all patients who qualify for coronarography have a normal coronary angiogram (Dickman \& Fass, 2006; Dobrzycki et al., 2005; Eslick et al., 2005; Eslick, 2008]. These data corroborate the most recent study by Patel et al. (2010), who conclude that the diagnostic yield of elective coronary angiography (about $20 \%$ of all procedures) amounted only to $38 \%$ (60\% did not influence patients' treatment), in spite of almost $70 \%$ of the patients undergoing elective coronary angiography having had positive findings on non-invasive examination (resting electrocardiography, echocardiography, computed tomography, or stress testing). They were also consistent with my recent work, which, among other things, has shown that exercise-provoked chest pain was accompanied by significant ST interval depression in about $60 \%$ of subjects with normal coronary angiogram, and $40 \%$ of subjects with significant coronary artery narrowing did not present ischaemic-like ECG changes (Budzyński, 2010c). 
The above-mentioned data can be summarized as follows:

- non-invasive diagnoses of chest pain and qualification for coronary angiography and percutaneous procedures are still not perfect;

- the most frequent causes of this symptom do not originate in the cardiovascular system; and

- $\quad$ symptom sources other than cardiac should be taken into account more frequently.

On the other hand, these conclusions should not change the prevailing principle that each chest pain episode must be recognized as a potential alarm symptom; the exclusion of lifethreatening conditions, including ischaemic heart disease, should remain the basis of chest pain diagnostic procedures. For this reason, it seems a better solution even to overuse coronary angiograms or coronary artery calcification scores (CAC) using multi-slice computer tomography, than miss the detection of severely ill patients. However, it should also always be taken into consideration that invasive cardiological diagnostic procedures give the most benefits to patients with acute chest pain episodes, and in patients with recurrent symptoms, extracardiac sources ought to be more frequently considered (Patel et al., 2010).

It is possible that changes in diagnostic algorithms of chest pain diagnosis and therapy not only decrease the prevalence of this symptom, but might also decrease the costs of health care. Such reductions would be considerable, as the medical procedures connected with chest pain symptoms utilize a noticeable part of health care resources. The annual cost of the medical care of patients with recurrent chest pain in the US ranges from $\$ 350$ million to $\$ 1.8$ billion (Leise et al., 2010), and has even reached \$3-8 billion (Eslick \& Talley, 2004; Eslick et al., 2005; Eslick, 2008; Liuzzo et al., 2005; Mant et al., 2004). In the UK, it consumes approximately $1 \%$ of the health care budget (Fox, 2005). However, the real costs of recurrent chest pain are greater because of the social expenditure connected with this symptom (Eslick \& Talley, 2004; Eslick et al., 2005; Eslick, 2008; Katerndahl, 2004). Within the one to five-year follow-up period, about $40 \%$ of patients with recurrent chest pain are hospitalized at least once due to chest pain, 30\% receive a subsequent coronary angiogram (Bugiardini et al., 2005), nearly $30 \%$ of patients are unemployed and receive a disability pension, and in $60 \%$ of individuals recurrent chest pain limits their physical activity, causing displeasure regarding physicians' competence in 66-81\% (Dickman \& Fass, 2006).

There may be a number of reasons for unsatisfactory data concerning the prevalence and treatment outcome in patients with recurrent chest pain. To counter this, the many wellknown causes of chest pain episodes ought to be analysed, as they have various degrees of clinical importance and may originate from cardiovascular system dysfunction (due to myocardial ischaemia or non-ischaemic reasons), the respiratory system, digestive tract, or begin in the skeleton (Cayley, 2005; Eslick \& Talley, 2004; Eslick et al., 2005; Eslick, 2008; Laird et al., 2004). Symptoms deriving from each of these sources may be further aggravated by reactions of depression or panic disorders (Dickman \& Fass, 2006; Fass, 2008; Fass \& Navarro-Rodriguez, 2008). Moreover, the respective causes of chest pain may coexist and overlap (e.g. the cardiovascular with the gastroenterological or musculoskeletal), and disorders of one system may disturb the function of the others, masking the true cause of symptom evoking. These complicated relationships connected with chest pain make it difficult to diagnose and treat the chest pain source, favour symptom recurrence, and increase resource utilization. Precision in the analysis of symptom characteristics remains the pivotal diagnostic method of chest pain origin because of the aforementioned low diagnostic yield of non-invasive cardiovascular examinations and elective coronarography (Patel et al., 2010). In particular, the localization, radiation and character of chest pain 
episodes should be evaluated, as well as any aggravating and alleviating factors (Potts \& Bass, 1995; Swap \& Nagurney, 2005). Angina pectoris is a particular type of chest pain. It is defined as precordial discomfort, sometimes radiating to the jaw or arm, which is provoked by effort, emotional stress, cold or wind, and withdraws after rest or nitroglycerine use. However, too many times it is forgotten that these criteria are applicable to chest pain episodes originating not only from the cardiovascular system, but also from the digestive tract, especially from the oesophagus, stomach and gall bladder. Moreover, angina pectoris may be caused by myocardial ischaemia, resulting not only from coronary artery narrowing, but also from extracardiac disorders, which leads to an imbalance between myocardial oxygen supply and requirement (e.g. anaemia, thyrotoxicosis). Anaemia is frequently secondary to many digestive tract diseases, such as acute and/or chronic bleeding from the alimentary tract (erosions, ulcers, neoplasm), malabsorption, maldigestion, blood sequestration or autoimmunological reactions. In this way, disorders of the digestive tract can also favour angina pectoris exacerbation. Therefore, although certain elements of the chest pain history are associated with increased (radiating to shoulder(s), or arms, or precipitation by exertion) or decreased (pain like stabbing, pleuritic, positional, or reproducible by palpation) likelihoods of a diagnosis of angina pectoris, none of them alone or in combination identify a group of patients, who do not need a further diagnostic testing (Swap \& Nagurney, 2005).

To summarize, angina pectoris is an important, prevalent symptom, utilizing enormous quantities of resources, which is considered all too frequently as a typical symptom of coronary artery disease (CAD), but rarely as a symptom of at least two types of digestive tract disease. The first group concerns diseases which evoke angina-like chest pain from the oesophagus, stomach and gall bladder by the stimulation of their chemo-, mechano-, and/or thermoreceptors; the second group manifests clinically as anaemia, which leads to insufficient oxygen supply to the heart. It is important to realize that both these kinds of digestive tract diseases may overlap with CAD, aggravating precordial symptoms or mimicking atherosclerosis progression. These gastroenterological aspects of angina pectoris will be analysed in this chapter in detail.

\section{Epidemiology}

Coronary artery disease (CAD) is the most frequent cause of morbidity and mortality in developed countries. As a result of such epidemiological data, almost each chest pain episode is considered as originating from the heart. However, recurrent, angina-like chest pain originating from e.g. the oesophagus is also a frequent problem in everyday practice, mainly due to the high prevalence of alimentary tract diseases in the general population. Recurrent chest pain which is non-cardiac in origin is defined as substernal chest pain in the absence of significant epicardial coronary artery stenoses (Eslick \& Talley, 2004; Eslick et al., 2005; Eslick, 2008; Dickman \& Fass, 2006; Fass, 2008; Hebbard, 2010; Leise et al., 2010). It is reported every year by about $13-30 \%$ of adults, without sex preference. It is experienced during a typical lifespan by approximately $20-40 \%$ of the population, with a decrease in prevalence with increasing age (Eslick \& Talley, 2004; Eslick et al., 2005; Eslick, 2008; Dickman \& Fass, 2006; Fass, 2008; Ruigómez et al., 2006, 2009). The majority of patients with recurrent chest pain which is non-cardiac in origin continue to report episodes of long-term symptoms. In the study by Potts and Bass (1995), 75\% of the surviving patients with recurrent chest pain and lack of obstructive coronary artery lesions continued to report the 
occurrence of precordial discomfort 11 years later, and 34\% reported weekly chest pain symptoms.

The most prevalent cause of non-cardiac chest pain (NCCP) is gastro-oesophageal reflux disease (GERD), which accounts for up to $60 \%$ of cases (Leise et al., 2010). The occurrence of its main symptom, heartburn, at least once per month is reported by about $36-44 \%$ of the adult population, $14 \%$ once per week, and $7 \%$ every day (Lemire, 1997). On the other hand, a chest pain sensation is experienced by about $37 \%$ of patients with heartburn occurring once per week, $30 \%$ of individuals with more seldom symptom occurrence, and about $8 \%$ without the feeling of pyrosis (Fass and Navarro-Rodriguez, 2008).

It is generally estimated that gastroenterological abnormalities have a similar prevalence in patients both with and without significant coronary artery narrowing, which shows a possibility to overlap e.g. GERD and CAD symptoms (Budzyński et al., 2008; Budzyński 2010a, 2010c; Cooke et al., 1998; Dobrzycki et al., 2005; Mehta et al., 1996; Ruigómez et al., 2006, 2009; Schofield et al., 1987, 1989). Only a few authors have suggested a lower coexistence of oesophageal disorders in subjects with CAD (Adamek et al., 1999; Battaglia et al., 2005). On the other hand, the probability of diagnosing the respective functional oesophageal disorders (GERD, motility disorders, visceral hypersensitivity) as a cause of non-cardiac chest pain (NCCP) depends on the location of the patient's consultation. They were the cause of non-cardiac chest pain (NCCP) in $0.6-25 \%$ of patients of general practitioners, in $46 \%$ of patients admitted to Cardiological Intensive Care Units because of acute chest pain, in $60-70 \%$ of patients with angina-like chest pain and a normal coronary angiogram, and in $30-80 \%$ of patients with obstructive coronary lesions and chronic precordial discomfort non-responsive to optimal anti-angina therapy (Budzyński et al., 2008; Dobrzycki et al., 2005; Rosztóczy et al., 2007; Świątkowski et al., 2004). Therefore, NCCP caused by gastrointestinal, mainly oesophageal, disorders may coexist with CAD in as many as $30-80 \%$ of patients. This is very high but clinically very important, as disease overlapping, which causes a great deal of confusion and clinical doubt, is related to at least three factors: the epidemiological, the pharmacological, and the pathophysiological (Budzyński et al., 2008).

Epidemiological causes of the frequent coexistence of digestive and cardiovascular disorders result from a high prevalence of diseases sourced from both systems and have similar risk factors. Both gastroenterological and cardiovascular diseases are found more frequently in older and obese patients, those suffering from hypertension, diabetes, and obstructive sleep apnoea, as well as in smokers, alcohol drinkers and caffeine over-users (Budzyński et al., 2008; Fass \& Dickman, 2006;). The frequent coexistence of gastroenterological and cardiovascular diseases also depends on pharmacological causes due to the adverse effects of drugs recommended in the therapy for both system disorders. It is generally known that calcium channel antagonists (e.g. amlodipine, verapamil and diltiazem), nitrates, blockers of alpha-1 adrenergic receptors, and betamimetics may decrease with lower oesophageal sphincter (LOS) pressure and favour gastro-oesophageal reflux, the most frequent cause of NCCP. It should also be taken into consideration that aspirin-induced gastropathy is a potential cause of NCCP (Hsiao et al., 2009). Its symptoms frequently disappear after empirical therapy with proton pump inhibitors (PPIs), but this has not been confirmed by all authors. Moreover, some medicines used in the treatment of gastroenterological disorders may show pharmacological or pharmacodynamic interactions with drugs recommended for cardiovascular diseases, e.g. omeprazole decreases the bioavailability of digoxin, warfarin and clopidogrel. The last interaction in particular caught the investigator's attention following publication by Juurlink et al. (2009), who reported a greater prevalence of acute 
coronary syndromes and myocardial infarction in patients taking omeprazole, rabeprazole or lansoprazole for the purpose of preventing gastrointestinal bleeding during dual antiplatelet therapy. Although recent publications have not confirmed the clinical importance of this interaction, their authors and panels of experts have recommended caution in coprescribing PPIs with clopidogrel (American College of Cardiology Foundation [ACCF], 2010; American Society for Gastrointestinal Endoscopy [ASGE], 2009; Bhatt et al., 2008; de Aquino Lima \& Brophy, 2010; Laine \& Hennekens, 2010). There is also divergent information concerning the interaction between PPIs and acetylsalicylic acid, showing no effect (Adamopoulos et al., 2009), an increase (Kasprzak et al., 2009), and a decrease (Würtz et al., 2010) in anti-platelet aspirin activity.

Finally, the high prevalence of the coexistence of cardiovascular and gastroenterological chest pain causes may also result from pathophysiological factors, mainly the inflammatory and neural pathways for linked angina (Chauhan et al., 1996; Hoff et al., 2010; Makk et al., 2000; Rosztóczy et al., 2007). They are connected in the mechanism of a vicious circle, in which gastro-oesophageal reflux induces myocardial ischaemia, and products of the anaerobic myocardial metabolism due to ischaemia in turn provoke gastro-oesophageal reflux, dysphagia, or hiccups (Hoff et al., 2010; Krysiak et al., 2008; Stec et al., 2010). These problems are explained in detail in a separate subsection (4b).

\section{Prognosis}

Patients with recurrent chest pain and normal coronary angiogram (i.e. NCCP) have a relatively good life expectancy prognosis. The 30-day mortality connected with this symptom is estimated at 0.3-1.1\% (Eslick \& Talley, 2004; Eslick et al., 2005; Eslick, 2008), the risk of major cardiovascular event (death, myocardial infarction) with an odds ratio (OR) amounting to 2.3 (95\% CI, 1.3-4.1) (Ruigómez et al., 2006, 2009), and the need for emergency coronary intervention amounting to approximately $4 \%$ (Hollander et al., 2007). However, in the recent study by Leise et al. (2010), patients with NCCP which is gastrointestinal in origin displayed less overall survival at all time points compared with their counterparts with NCCP of unknown origin, specifically $70.1 \%$ at 10 years and $51.8 \%$ at 20 years. This was mainly explained by the overlapping of cardiovascular risk factors in patients with GERD. Whereas, in the paper by Munk et al. (2008), the 10-year relative risk of hospitalization for ischaemic heart disease (a discharge diagnosis of myocardial infarction, angina and/or heart failure) following a normal upper endoscopy among 386 Danish patients with unexplained chest/epigastric pain was 1.6 (95\% CI, 1.1-2.2), compared with 3,973 population controls. The adjusted mortality rate ratio was the greatest within the first year after an upper endoscopy and amounted to 2.4 (95\% CI, 1.3-4.5). The difference faded with time, and the 10-year adjusted mortality rate ratio amounted to 1.1 (95\% CI, 0.9-1.5). The increased mortality among these patients stemmed from alcohol dependence, pneumonia (not as a complication of the endoscopy), and lung cancer, but not IHD.

On the other hand, patients with recurrent chest pain have a poor prognosis in relation to symptoms receding. They also present a high annual rate (50-81\%) of chest pain recurrence (Ruigómez et al., 2006, 2009). Unemployment connected with this symptom occurrence concerns 41-50\% of patients (Eslick \& Talley, 2004; Eslick et al., 2005; Eslick, 2008; Fass, 2008; Fass \& Dickman, 2006; Fass \& Navarro-Rodriguez, 2008).

The aforementioned data justify undertaking the effort to establish the most precise diagnosis of the source of recurrent chest pain. Such a procedure makes it possible to calm 
the patient by explaining some of the non-dangerous reasons for chest pain occurrence. Moreover, the diagnosis of the real source of distressing complaints makes possible a specific treatment recommendation. It is effective in different degrees in about $80 \%$ of patients, decreasing NCCP episode recurrence and hospitalization necessity, improving patients' health-related quality of life, and reducing the health care costs (Cheung et al., 2009; Dickman \& Fass, 2006; Fass, 2008; Fass \& Dickman, 2006; Fass \& Navarro-Rodriguez, 2008; Laheij et al., 2003; Sheps et al., 2004). The diagnosis of GERD as a source of NCCP and the recommendation of the prolonged use of PPIs has decreased the risk of chest pain recurrence by $46 \%$ and the number of patients needing to be treated (NNT) has amounted to 3 (95\% CI, 2-4) (Cremonini et al., 2005). Whereas, undiagnosed chest pain has been shown to increase the risk of hospitalization due to CAD and all-cause mortality during 10 years of follow-up (Munk et al., 2008).

\section{Pathophysiology}

As has been mentioned, angina-like chest pain presents typical features of visceral pain which may be symptomatic of both ischaemic heart diseases and digestive tract disorders. To the first group of diseases belong both patients with coronary artery narrowing, known as patients with CAD, and subjects with a normal or almost normal coronary artery angiogram ("non-visible", "non-obstructive atherosclerotic coronary disease" (Bataglia et al., 2005). Chest pain occurring in patients with a normal coronary angiogram is frequently called NCCP. It may be caused by extracardiac diseases, mainly digestive tract disorders (Labenz, 2010). However, it should also be taken into account that it may also be sourced by missed coronary angiogram lesions, microvascular coronary dysfunction (cardiac syndrome $\mathrm{X}$ ), coronary spasm, or secondary angina (e.g. aortic valve dysfunction, tachycardia, thyrotoxicosis, anaemia) (Bugiardini et al., 2005).

The relationships between the digestive tract and cardiovascular system are complicated and stem from epidemiological, pharmacological (described above) and pathophysiological factors. Each of them concerns both patients with a normal coronary angiogram and with $\mathrm{CAD}$, and may lead to symptom mimicry and overlapping. There are at least three pathomechanisms evoking angina-like chest pain in the course of digestive tract diseases:

a. chest pain is evoked by stimulation of digestive tract pain receptors and mimics angina;

b. digestive tract diseases via neural and inflammatory pathways disturb myocardial perfusion and evoke chest pain which is cardiac in origin due to myocardial ischaemia, although the true cause of the symptoms is located e.g. in the oesophagus;

c. chest pain, cardiac in origin, is secondary to an imbalance between oxygen supply and myocardial demand due to anaemia, which is frequently secondary to various diseases of the alimentary tract.

\subsection{Angina-like chest pain which is digestive tract in origin}

The most common example of the first pathophysiological group of chest pain is GERD, responsible for 50-60\% of the causes of NCCP (Dickman \& Fass, 2006; Eslick \& Talley, 2004; Eslick et al., 2005; Eslick, 2008; Fass \& Dickman, 2006; Fass \& Navarro-Rodriguez, 2008; Hebbard, 2010; Tipnis et al., 2007; Tougas et al., 2001). The main symptoms of GERD are heartburn (pyrosis), regurgitation, or the "reflux chest pain syndrome" distinguished by the 
definition and classification of GERD developed by the Montreal Consensus Group in 2006 (Vakil et al., 2006). The other diseases which may mimic angina pectoris, frequently known as non-GERD-related NCCP, are as follows: oesophagitis caused by non-reflux-related factors (such as infections or being drug induced); oesophageal motility disorders; hiatal hernia; gastric and duodenal ulcer disease; drug- (aspirin, non-steroidal anti-inflammatory drugs) induced gastropathy; acquired hepato-diaphragmatic migration of the hepatic flexure of the colon (Chilaiditi's syndrome); cholecystitis; and acute pancreatitis (Dickman \& Fass, 2006; Drewes et al., 2006; Eslick \& Talley, 2004; Eslick et al., 2005; Eslick, 2008; Fass \& Dickman, 2006; Fass \& Navarro-Rodriguez, 2008; Ruigómez et al., 2006, 2009, , Sorrentino et al., 2005). The Rome Criteria III also distinguish a particular kind of non-cardiac chest pain, called "functional chest pain of presumed esophageal origin", which is defined as midline discomfort which is not of burning quality, lasting at least three months, with an onset at least six months prior to diagnosis, and an absence of GERD and histopathology-based oesophageal motility disorders (Drossman, 2006). My own observations have also shown that exerciseinduced oesophageal motility disorders, such as exercise-provoked oesophageal spasm (EPOS) or exercise-provoked gastro-oesophageal acid reflux, may play some role in the pathogenesis of angina-like chest pain in at least $22 \%$ of patients with recurrent symptoms (Budzyński, 2010a, 2010b). It is worth underlining that nearly $80 \%$ of the patients with functional chest pain simultaneously present symptoms of other functional disorders, primarily irritable bowel syndrome $(27 \%)$ and abdominal bloating $(22 \%)$ (Dickman \& Fass, 2006; Fass \& Navarro-Rodriguez, 2008). Their coexistence with chest pain may help in appropriate diagnoses. The aforementioned mainly oesophageal and gastric abnormalities may be accompanied by endoscopically visible morphological changes in mucosa or not. Some of these differences in the clinical course of GERD have been classified by the Global Consensus Group in Montreal, which, among oesophageal syndromes, enumerates: (a) symptomatic syndromes (without oesophageal erosions) concerning approximately $60 \%$ of patients, and (b) syndromes with oesophageal injury (erosive oesophagitis, oesophageal strictures, Barrett's oesophagus, oesophageal adenocarcinoma) (Sarkar et al., 2004; Vakil et al., 2006). In this way, oesophageal erosions are present in $10-70 \%$ of patients with NCCP (Fass and Navarro-Rodriguez, 2008); therefore, a lack of endoscopic abnormalities does not exclude both a GERD and an oesophageal origin of NCCP.

The above-mentioned diseases of the oesophagus, stomach, colon, pancreas or gall bladder evoke angina-like chest pain by the activation of local pain receptors, both chemical and mechanical (e.g. ASIC, TRPV, P2X and TREK), by inflammatory mediators, kinins, pepsin, bile acids, changes in oesophageal $\mathrm{pH}$, pressure (oesophageal distension, volume, shear stress), or temperature, and by the induction of a secondary local motility response, expressed by hypermotility, oesophageal long muscle shortening, high amplitude oesophageal peristalsis, oesophageal distension or prolonged oesophageal contractions (Drewes et al., 2006; Sifrim et al., 2007; Tipnis et al., 2007). However, the intensity of the clinical manifestation of these disorders is related to the threshold of receptor stimulation. Its decrease is frequently known as visceral hypersensitivity (Dickman \& Fass, 2006; Drewes et al., 2006; Eslick \& Talley, 2004; Eslick et al., 2005; Eslick, 2008; Fass \& Dickman, 2006; Fass \& Navarro-Rodriguez, 2008). It is enumerated as one of the main pathomechanisms of symptoms in the course of cardiac syndrome $X$, mitral prolapse syndrome, irritable oesophagus, functional dyspepsia, irritable bowel syndrome (IBS), and fibromyalgia (Katerndahl, 2004; Hammet et al., 2003; North et al., 2007). The recently published investigation by Nasr et al. (2010) using a balloon distension test has shown that 
oesophageal hypersensitivity plays an important role in $75 \%$ of patients with functional (non-cardiac and non-reflux) chest pain. The basis of this disorder is a decrease in the pain threshold, both at the central and peripheral perception levels (Dickman \& Fass, 2006; Fass \& Dickman, 2006; Sheps et al., 2004; Sifrim et al., 2007). The range of the change in this threshold may be modulated by a number of factors influencing the function of the braingut axis (Mayer \& Tillisch, 2011; Sheps et al., 2004). These factors are as follows:

- personal (female gender, age between 15-34, incorrect response of the autonomic nervous system, psychiatric disorders, stress, sleep disturbances, oesophagitis or gastritis, mucosal mastocyte infiltration, allodynia);

- $\quad$ environmental (stress, Helicobacter pylori (Hp) infection, dietary factors, especially a fatty diet) (Remes-Troche, 2010; Sheps et al., 2004; Sifrim et al., 2007; Tougas et al., 2001).

The modulation of the central pain threshold in patients with unexplained chest pain, CAD and occult GERD may also be related to chronic receptor stimulation and/or the coexistence of psychiatric disorder (Drewes et al., 2006; Lenfant, 2010; Remes-Troche, 2010). Sarkar et al. (2004) have reported a decrease in allodynia after therapy with PPIs. Whereas, Makk et al. (2000) have shown a greater oesophageal acid sensitivity (a lower pain threshold) in individuals with a normal coronary angiogram and patients undergoing coronary angioplasty than in those with coronary artery narrowing and undergoing coronary angiography alone. Moreover, in approximately $70 \%$ of patients with NCCP, anxiety, depression or somatization have been observed (Dickman \& Fass, 2006; Eslick \& Talley, 2004; Eslick et al., 2005; Eslick, 2008; Fass \& Dickman, 2006; Fass \& Navarro- Rodriguez, 2008; Katerndahl, 2004). In these subjects, NCCP amelioration and a decrease in pain hypersensitivity were found after therapy with antidepressants such as imipramine, sertraline or trazodone in controlled and uncontrolled investigations (Dickman \& Fass, 2006; Eslick \& Talley, 2004; Eslick et al., 2005; Eslick, 2008; Fass \& Dickman, 2006; Fass \& Navarro-Rodriguez, 2008). Psychiatric disorders, besides decreasing the pain threshold, may also evoke chest pain by hyperventilation and secondary coronary arteries and/or oesophageal spasm (Chauhan et al., 1996). As a result, the following markers of a psychiatric basis for recurrent chest pain were proposed: atypical character of symptoms, female gender, younger age, a high level of anxiety, and a neurotic personality (Ringstrom and Freedman, 2006).

The character of the pain occurring in the course of digestive tract diseases may be similar to that of acute coronary syndrome or recurrent stable angina pectoris. The simple explanation of this fact involves the visceral features of the pain and the anatomical localization of the heart and oesophagus in the chest. The latter factor causes the overlap of the head areas in brain sensory representations of the oesophagus and heart. However, the anatomical relationships between the oesophagus and the heart may produce symptoms in some more immediate way. Namely, the extended left atrium, due to e.g. mitral valve disease or left ventricle cardiac failure, may press the oesophagus, evoking changes in intra-oesophageal pressure, mechanical receptor stimulation or disturbance in the oesophageal passage, known as cardiac dysphagia or odynophagia (angina-like chest pain which is oesophageal in origin). These disorders may also, through pressure receptor stimulation, activate vagal neural reflexes leading to a decrease in myocardial perfusion (angina-like chest pain which is cardiac in origin), described in detail in part b of this section. On the other hand, an enlarged oesophagus, due to e.g. achalasia or oesophageal carcinoma, producing left atrium compression, may also evoke local ischaemia of the atrial muscle and/or activation of mechano-electrical coupling, raising the local dispersion in the functional potential of atrial 
muscle cells and producing re-entry loops. These disorders may manifest clinically as chest pain or arrhythmia (Budzyński \& Pulkowski, 2009; Duygu et al., 2008; Upile et al., 2006).

To summarize, chest pain originating from the oesophagus may be similar to cardiacderived angina pectoris. It may be caused by activation receptors in the digestive tract and motor dysfunction of the oesophageal wall. The intensity of the clinical manifestation of these disturbances is modulated by the frequent presence of visceral hypersensitivity. These complicated relationships have explained the confusion and misdiagnosis often accompanying chest pain diagnosis.

\subsection{Angina-like chest pain which is cardiac in origin but induced by digestive tract disorders}

Apart from the above-mentioned resemblance of chest pain originating from the heart and the oesophagus, as well as the overlapping of symptoms evoked both by cardiovascular and alimentary tract diseases, the clinical doubts concerning the true source of chest pain, whether cardiac or oesophageal, are augmented by the second of the distinguishing pathomechanisms of chest pain caused by diseases of the digestive tract: the activation of neural and inflammatory pathways which in turn may decrease myocardial perfusion.

Neural reflex loops between the heart and oesophagus have been found both in human and animals. Stimulation of oesophageal chemo-, mechano- and thermoreceptors, apart from provoking chest pain of oesophageal origin in about half (49-56\%) of patients with a normal coronary angiogram (cardiac syndrome $\mathrm{X}$ ), coronary artery spasm or obturative lesions in coronarography (patients with $\mathrm{CAD}$ ), may also activate vagally-mediated, viscero-visceral neural reflexes (e.g. cardio-oesophageal reflex) (Budzyński et al., 2008; Budzyński, 2010c; Charng et al., 1988; Chauhan et al., 1996; Dobrzycki et al., 2005; Drewes et al., 2006; Fass \& Dickman, 2006; Makk et al., 2000; Manfrini et al., 2006; Rasmussen et al., 1986; Rosztóczy et al., 2007) or a viscero-somatic neural reflex (Drewes et al., 2006; Jou et al., 2002). The first reflex may evoke ischaemic chest pain, cardiac in origin, resulting from diminished myocardial perfusion and secondary to pre-arteriole contraction (Chauhan et al., 1996; Makk et al., 2000; Rosztóczy et al., 2007); the second, viscero-somatic reflex, causes an increase in the spinotrapezius muscle contractions both after cardiac and oesophageal receptor stimulation via convergent pathways in the sympathetic nerves (Jou et al., 2002). The last reflex is responsible for the somatic component of pain evoked by the stimulation of visceral, cardiac or oesophageal receptors. Moreover, afferent stimulus originating from the oesophagus, stomach or gall bladder may also interfere with stimulus derived from the heart in the spinal cord, which is a further cause of the resemblance of symptoms deriving both from the digestive tract and the cardiovascular system (Sheps et al., 2004).

However, the aforementioned reflexes (neural loops) do not function in all subjects but only in about half (Chauhan et al., 1996; Makk et al., 2000; Mehta et al., 1996; Rosztóczy et al., 2007); this results from the modulation of the impulse transmission along nervous pathways by coexistent mental or psychiatric disorders, the balance between the sympathetic and parasympathetic parts of the autonomic nervous system and the threshold of receptor stimulation, which is decreased in patients with visceral hypersensitivity. These suggestions are supported by papers showing a relatively high prevalence of panic or depressive disorders in approximately half of patients, with both cardiovascular and digestive tract diseases (Lenfant, 2010). Autonomic nervous system imbalance has also been found in up to half of patients with functional chest pain (Nasr et al., 2010; Tougas et al., 2001), Helicobacter 
pylori infection (Budzyński et al., 2004), functional dyspepsia, irritable bowel syndrome (Mayer \& Tillisch, 2011), or chronic heart failure. Modulation of visceral reflex activity by these cofactors may cause the activity of cardio-oesophageal reflexes not to manifest clinically in all subjects. Dobrzycki et al. (2005) have suggested that those most susceptible to the clinically important effect of cardio-oesophageal reflex activity seem to be patients with CAD, because in this patient group even slight coronary reserve impairment may be clinically important. On the other hand, Rosztóczy et al. (2007), using a combination of an oesophageal acid perfusion test and transoesophageal Doppler echocardiographic coronary flow measurement, have shown that $49 \%$ of subjects presented coronary spasm in response to oesophageal acidification more frequently than either epicardial coronary artery disease or microvascular coronary disease, probably due to signs of cardio-oesophageal reflex activation. In the gastroenterological work-up, they had higher DeMeester scores, an increased number of reflux episodes, a fraction time below $\mathrm{pH} 4$, and prolonged acid reflux episodes. These data corroborate the paper by Sarkar et al. (2004), who observed the reversible influence of chronic oesophageal mucosa exposure to acid on the visceral pain threshold, one of the mechanisms modulating visceral, vagally-mediated reflex activity. The importance of the role of the parasympathetic nervous system for subjects with NCCP has also been shown by Tougas et al. (2001). In their study, 67\% of patients with a normal coronary angiogram presented angina-like chest pain after oesophageal acid infusion. Chest pain in "acid-sensitive patients" was accompanied by a higher baseline heart rate and lower baseline vagal activity (estimated using heart rate variability [HRV] analysis) than "acidinsensitive patients". During acid infusion, vagal cardiac outflow (expressed as a high frequency component of HRV) increased in "acid-sensitive" but not in "acid-insensitive" patients (Tougas et al., 2001).

The endpoint of the aforementioned complicated influence of the nervous system on the interrelationships between the cardiovascular and alimentary systems is myocardial ischaemia, which may manifest clinically in $49-56 \%$ of patients as angina pectoris, arrhythmia and syncope (Chauhan et al., 1996; Cubattoli et al., 2009; Cuomo et al., 2006; Makk et al., 2000; Mehta et al., 1996; Rosztóczy et al., 2007). This symptomatic decrease in myocardial perfusion after oesophageal stimulation by acid was produced by epicardial coronary artery spasm (Rosztóczy et al., 2007) or by contraction of the prearterioles (Chauhan et al., 1996). The neural pathway for these effects (so- called linked angina) was proven by the lack of similar perfusion changes in heart transplant recipients (Chauhan et al., 1996). However, the aforementioned reflexive decrease in myocardial perfusion was accompanied by ischaemic electrocardiographic (ECG) changes in only a few works (Budzyński et al., 2008; Dobrzycki et al., 2005; Rosztóczy et al., 2007; Singh et al., 1992; Świątkowski et al., 2004).

However, the above-described mechanism is only the first on the arc of the cardiooesophageal loop of feedback. The second, opposite arm of this loop may be stimulated by the products of anaerobic myocardial metabolism, mainly bradykinin (Caldwell et al., 1994; Krysiak et al., 2008), invasive cardiac manoeuvres, manipulation, coronary angioplasty (Makk et al., 2000) or cardiac arrhythmia (Stec et al., 2010). Such activation may lead to reflexive oesophageal motility disorders or a decrease in lower oesophageal sphincter (LOS) pressure, which facilitates gastro-oesophageal reflux occurrence, changes in oesophageal $\mathrm{pH}$, potential reflexive activation of a cardio-oesophageal reflex and a reduction in myocardial perfusion (Caldwell et al., 1994). Described as reflexive, bidirectional, neurohormonal mechanisms connect the pathogenesis of the digestive tract and cardiovascular 
diseases in a vicious circle. Moreover, some studies have shown that the described associations between oesophageal and vascular spasm may also result from myogenic mechanisms and may be an overall effect of smooth muscle hypercontractility, depending on the individual concerned (Adamek et al., 1998a, 1998b, 1999; Makk et al., 2000; Manfrini et al., 2006; Rasmussen et al., 1986). The myogenic component of coronary-oesophageal interrelationships has been suggested by the coexistence of oesophageal spasm alongside coronary artery spasm, hypertension, migraine and Raynaud's symptoms.

The occurrence of angina-like chest pain, as well as other cardiac symptoms such as arrhythmia, or syncope may also be secondary to inflammatory factors often deriving from the digestive tract. The role of inflammatory processes in cardiovascular disease pathogenesis has been investigated for many years. At least two mechanisms have been distinguished for the influence of inflammation on cardiac function: local and systemic. The first has been mentioned by Weigl et al. (2003), who have suggested the possibility of local inflammatory process propagation through the oesophageal wall producing local pericarditis or atrial myocarditis. These histological abnormalities can be a substrate of chest pain or arrhythmia (Navarese et al., 2010; Stőlberger \& Finsterer, 2003). However, there is more to be said for the role of a systemic inflammatory response in the pathogenesis of chest pain which is cardiac in origin but evoked or intensified by digestive tract diseases. Systemic inflammatory factors known as cytokines (e.g. TNF-alpha, IL-1, IL-6) or adhesion molecules (e.g. VCAM-1, ICAM-1) are involved in the pathogenesis of atherosclerosis, endothelial dysfunction, and cardiac arrhythmia, mainly atrial fibrillation. Their synthesis may be stimulated in the course of many of the diseases of the alimentary tract, such as periodontal diseases, oesophagitis, gastritis, ileitis, inflammatory bowel diseases, liver cirrhosis, pancreatitis, and neoplasm (Shanker \& Kakkar, 2009; Stőlberger \& Finsterer, 2003). Some reports, including my own data, have also shown the unfavourable effect of Helicobacter pylori infection, not only on the course of digestive tract diseases, but also on the course of recurrent angina-like chest pain (Budzyński, 2011), changes in autonomic nervous system balance (Budzyński et al., 2004) and atherosclerosis progression (Franceschi et al., 2009). CagA seropositivity has been significantly and positively associated with the occurrence of acute coronary events, atherosclerosis progression and arrhythmia prevalence (Bunch et al., 2008a, 2008b; Francesci et al., 2009; Miyazaki et al., 2006). The positive relationship between Hp infection and cardiac syndrome X (Celik et al., 2010; Eskandarian et al., 2006; Rasmi \& Raeisi, 2009) has also been reported but not confirmed by others (Saleh et al., 2005). Whereas, Sandifer et al. (1996), based on the results of the EUROGAST Study Group, had shown a negative association between the seroprevalence of antibodies to Hp and the death rate from ischaemic heart disease.

Numerous mechanisms for the influence of $\mathrm{Hp}$ on atherosclerosis complications have been suggested. They may act directly on atherosclerotic plaques, as suggested by the results of Kowalski et al. (2001), who revealed the presence of Hp DNA in atherosclerotic lesions and an increase in coronary artery diameter after microorganism eradication. It has also been implied that mimicry occurs between the cytotoxin-associated gene-A (CagA) antigen expressed by some $\mathrm{Hp}$ strains and the protein presented in atherosclerotic plaques (Franceschi et al., 2009). Hp infection, similarly to periodontal infection (Shanker \& Kakkar, 2009) or the hepatitis C virus (Ramdeen et al., 2008), may also act as one amongst a number of factors taking part in the mechanisms of pathogen burden through the following: nonspecific inflammatory pathway stimulation (e.g. hs-CRP increase); the induction of endothelial and microvascular dysfunction; an increase in adhesion molecule expression 
(e.g. VCAM-1, ICAM-1); the over-synthesis of pro-atherogenic cytokines (e.g. IL-1 beta, IL-6, TNF-alpha); changes in autonomic nervous system balance (Budzyński et al., 2004; Budzyński, 2011; Celik et al., 2010; Rasmi \& Raeisi, 2009); and the production of metabolic abnormalities, such as hypertriglyceridaemia, increased LDL cholesterol levels, plasma lipid oxidation, hyperfibrinogenaemia, altered blood coagulation and leukocytosis. The role of Hp infection as a cause of myocarditis and ECG changes in patients with persistent chest pain has also been reported (Navarese et al., 2010). Apart from the aforementioned mechanisms, Hp infection may also affect the occurrence of angina-like chest pain which is gastroenterological in origin, being one of the pathogenic factors of gastritis, gastric and duodenal ulcer disease. Hp infection may also play a role in GERD pathogenesis via impaired vagal control of LOS pressure and a decrease in the release of ghrelin, a prokinetic hormone (Thor \& Blaut, 2006).

The described systemic inflammatory process mediators, e.g. deriving from the digestive tract, could influence cardiac symptom occurrence, not only by direct action on the vascular wall, but also via neuroimmune- endocrine crosstalk (Collins et al., 2009; Grundy et al., 2006; Marques et al., 2010; Wood, 2007). Inflammation mediators, especially cytokines such as TNF-alpha, interleukin-1 and interleukin-6, may stimulate both the hypothalamus and brain stem. The outcome of the first is the activation of the pituitary-suprarenal axis, which leads to increased cortisol and adrenalin secretion, and of the second is sympathetic activation. The consequence of such neuroendocrine stimulation may be chest pain, myocardial infarction, arrhythmia, sudden death or an increase in intestinal permeability due to digestive tract ischaemia. Its effect may in turn be an increase in cytokine secretion and the activation of immunological cells: lymphocytes, monocytes, macrophages and granulocytes possessing surface receptors for a number of neuroendocrine products. These can then stimulate vessel walls, induce endothelial dysfunction, atherosclerotic plaque instability and in turn produce neuroendocrine imbalance (Marques et al., 2010; Saleh et al., 2005). In this way, the aforementioned relationships involve the cardiological and gastroenterological symptoms in the second neuroimmune-endocrine vicious circle mechanism.

In summary, neural loops, inflammatory processes and neuroimmune-endocrine crosstalk activated by digestive tract disorders may be the second group, in addition to digestive tract abnormalities, of important factors evoking chest pain which is cardiac in origin. It may result from myocarditis and/or a progression or reversible reduction in myocardial perfusion. These processes may play a role in patients both with and without significant coronary artery narrowing.

\subsection{Angina-like chest pain which is cardiac in origin but secondary to anaemia caused by diseases of the alimentary tract}

The main cause of ischaemic heart disease and its typical symptom of angina pectoris is an imbalance between coronary blood supply and myocardial requirement. This shows that besides a decrease in blood delivery to the myocardium, angina-like chest pain may also be evoked or exacerbated by inadequate oxygen supply due to anaemia. Rapidly or slowly progressing anaemia may be a symptom of many digestive tract diseases, both of the upper and lower parts. It may be an effect of bleeding, malabsorption, maldigestion, blood sequestration or autoimmunological reactions (Zhu et al., 2010). For this reason, diagnostic procedures for the digestive tract, including biochemical and serological examinations, ultrasonography, panendoscopy, colonoscopy, and in special cases capsule endoscopy and single or double balloon enteroscopy, should be recommended for each male, 
postmenopausal women, and younger females when the quantity of blood loss during menstruation is insufficient to explain the presence of anaemia (Zhu et al., 2010).

However, both cardiologists and gastroenterologists should also take into account that acute bleeding into the digestive tract or slowly progressing iron deficiency anaemia may also be a symptom of the haemorrhagic complications of the anti-thrombotic therapy (e.g. aspirin, clopidogrel, heparin, bivalirudin, etc.) which is fundamental in the treatment of acute coronary syndromes and stable angina pectoris (Dai et al., 2009; Nema et al., 2008). Of these complications, $50 \%$ occur in the digestive tract (To et al., 2009). Prior to endoscopic procedures, especially with a high risk of haemorrhagic complications (e.g. polypectomy or mucosal resection), the risk of the discontinuation of dual anti-platelet therapy in particular should be estimated (ASGE, 2009; ACCF, 2010; Bhatt et al., 2008). This is very important, as clopidogrel withdrawal may lead to cardiac stent thrombosis in $15-40 \%$ of cases; it is associated with a myocardial infarct rate of $50 \%$ and a related death rate of approximately 20\% (ASGE, 2009). Therefore, in such clinical situations, consultation between cardiologist and gastroenterologist is needed to avoid patients being treated from a single organ perspective of the relative risks (cardiology vs. gastrointestinal) but with a more global balanced risk assessment instead to optimize patient outcomes.

The above deliberation shows the need for accuracy in evaluating angina pectoris symptom pathomechanisms (primary or secondary) to avoid the iatrogenic, clinically overt or silent haemorrhagic complications of anti-thrombotic drugs. Misdiagnosis or the inadequate taking of a medical history may lead to anaemia occurrence or aggravation, an increase in chest pain severity, unnecessary coronary angiogram performance, or death during haemorrhagic shock. One potential clinical scenario may take the following course: angina pectoris (stable or acute coronary syndrome) + latent digestive tract disease $\rightarrow$ treatment with aspirin and clopidogrel and/or warfarin or heparin $\rightarrow$ haemorrhagic complications (clinically overt or silent) $\rightarrow$ secondary anaemia and/or haemodynamic complications $\rightarrow$ exacerbation of chest pain severity $\rightarrow$ coronary angiogram performance, percutaneous coronary intervention and the need for prolonged dual anti-platelet therapy $\rightarrow$ an increase in the intensity of bleeding from the digestive tract, anaemia aggravation and a further increase in angina pectoris severity. In this way, clinically overt or latent bleeding from the digestive tract and secondary anaemia, besides the aforementioned neural cardiooesophageal loop and neuroimmune crosstalk, may be the third vicious circle mechanism, in which gastroenterological disorders, exacerbated or complicated by anti-platelet or antithrombotic treatment, may increase angina pectoris severity.

\section{Diagnosis}

According to current opinion, all patients with chest pain should first be evaluated for a cardiac cause of their symptoms (Fass \& Dickman, 2006; Potts \& Bass, 1995). To make this easier, some authors recommend estimating the probability of cardiac chest pain origin on the basis of tests with nitroglycerine and the number of atherosclerosis risk factors. In spite of some doubts concerning the low specificity of a nitroglycerine test (Fass \& Dickman, 2006), chest pain disappearance within five minutes after one dose of $400 \mathrm{mcg}$ of shortacting nitrates, a cardiac or gastroenterological symptom source should be considered, rather than a psychiatric one. Afterwards, if the tests present more than two atherosclerosis risk factors, a cardiological diagnostic pathway should be taken first (an ECG, stress test, stress echocardiography and angiography being the proposed series of steps). However, if 
patients have fewer than three risk factors, the following sequence of procedures in the diagnosis of angina-like chest pain presumed to be of oesophageal origin is proposed: complete the Carlsson-Dent questionnaire; empirical therapy with proton pump inhibitors (PPIs), known as the "omeprazole test"; endoscopy; 24-hour ambulatory oesophageal pHmetry; 24-hour multichannel intraluminal oesophageal impedance with pH-metry examination, in particular with an analysis of the symptom index (SI) or symptom association probability (SAP); stationary oesophageal manometry; 24-hour oesophageal manometry with SI or SAP evaluation; brain imaging; as well as psychiatric examination (Dickman \& Fass, 2006; Eslick \& Talley, 2004; Eslick et al., 2005; Eslick, 2008; Fass \& Dickman, 2006; Fass \& Navarro-Rodriguez, 2008; Hewson et al., 1990; Oranu and Vaezi, 2010; Sheps et al., 2004). The recently proposed diagnostic methods for NCCP presumed to be of oesophageal origin are as follows: a magnifying endoscopy with high resolution imaging (to show oesophageal mucosa microerosions), prolonged oesophageal $\mathrm{pH}$-metry using the wireless Bravo method, high resolution manometry, high frequency intraoesophageal ultrasonography (HFIUS), impedance planimetry, and multi-slice computer tomography. However, their usefulness in the diagnosis of chest pain requires confirmation (Dickman \& Fass, 2006; Fass \& Dickman; George \& Movahed, 2010; Hebbard, 2010).

The Carlsson-Dent questionnaire (CDQ) is a simple but old diagnostic tool for the detection of GERD, the main cause of NCCP without alarm symptoms or the suspicion of the other possible GERD complications (Numans \& de Wit, 2003). It has been validated in European patients. In comparison with oesophageal pH-metry and endoscopy, it is estimated as having good sensitivity (89-94\%) and a positive predictive value (55-90\%) for the detection of GERD.

Empirical therapy with a triple standard dose of PPI (e.g. 40-0-20 mg of omeprazole) gives valuable information about GERD being the reason of NCCP. It is a simple, available, sensitive and cost-effective tool, but the specificity is insufficient to put this test into practice as the single objective diagnostic criterion, mainly due to risks connected with false undiagnosed CAD. Its sensitivity and specificity in the diagnosis of GER-related chest pain in comparison with oesophageal $\mathrm{pH}$-metry reaches $69-95 \%$ and $57-86 \%$ respectively (Fass \& Dickman, 2006; Dickman et al., 2005; Wang et al., 2005). However, this test may be less valuable for patients in whom symptoms appear less frequently than twice a week (Cremonini et al., 2005). On the other hand, taking this limitation into account, testing with PPIs can be used as a diagnostic (lasting 1-2 weeks) and as a diagnostic-therapeutic test (1-4 months of "therapy as investigation"). Chest pain disappearance after the respective period should be interpreted as confirmation of clinical associations between acid regurgitation and symptom occurrence. The economic aspects of NCCP diagnosis also see much of the use of this test in clinical practice. A one-week test with PPI decreased the overall costs of NCCP diagnosis by $\$ 573-1,338$, mainly due to the reduction in the number of panendoscopies performed (by 81\%), 24-hour oesophageal pH-metry (by 79\%), and remains the functional diagnostic examination for NCCP (Fass \& Navarro-Rodriguez, 2008). Unfortunately, this test was not validated in patients with CAD, in whom GERD symptom prevalence and overlapping seems to be clinically important. Of this group, GERD-related chest pain episodes were found in 30-46\% of patients (Budzyński et al., 2008; Dobrzycki et al., 2005). These overlapped with chest pain of cardiac origin, being indistinguishable from angina pectoris resulting from myocardial ischaemia and leading to symptom persistence. In the RITA-3 study, $24 \%$ of participants still reported angina in the II-IV class according to the CCS classification over one year after percutaneous coronary intervention (Kim et al., 2005; 
Poole-Wilson et al., 2006). In light of this, such empirical testing with PPIs seems to be worth recommending for each patient with refractory angina. Unfortunately, the recent recommendation concerning refractory angina by Kones (2010) does not refer to such a possibility. However, due to possible potential dangerous interactions between clopidogrel and PPIs, this test should be avoided in patients on dual anti-platelet therapy (ACCF, 2010; Bhatt et al., 2008). Our own investigations have also shown the necessity for careful interpretation of testing with PPIs due to an increase found in nitric oxide bioavailability after rabeprazole therapy (Kłopocka et al., 2006) and beta-endorphin plasma levels (Budzyński et al., 2010). These substances produced during therapy with PPIs may mask the true chest pain source, including that of cardiac in origin.

Endoscopy is the most recommendable exploratory procedure in patients with GERD symptoms, fundamentally heartburn and regurgitation, especially when alarm symptoms appear. On the other hand, 50-75\% of GERD and 10-70\% of NCCP patients have a normal endoscopy examination (non-erosive GERD) (Dickman \& Fass, 2006; Fass \& Dickman, 2006). The recent report by Dickman et al. (2007a), on the basis of the results of upper endoscopy undergone for NCCP and GERD in a group of respectively 3,688 and 32,981 consecutive patients, has shown a normal upper endoscopy in $44.1 \%$ of NCCP patients and $38.8 \%$ of those with GERD. Of the NCCP group, $28.6 \%$ had a hiatal hernia, $19.4 \%$ erosive oesophagitis, $4.4 \%$ Barrett's oesophagus, and 3.6\% stricture/stenosis. Peptic ulcers were found in $2 \%$ of the NCCP patients. Thus, endoscopy does not appear to be dispensable in a large group of patients with NCCP. It is likely that the new generation of endoscopy equipment - magnifying endoscopy - would be helpful in the detection of oesophageal mucosa microerosions, but it is unable to provide certainty of the clinically important association between NCCP and oesophageal lesions found. Therefore, the greatest clinical importance of endoscopy is the possibility of diagnosis, including mucosal biopsy and treatment of the morphologic cause of alarm symptoms and the source of haemorrhaging from the digestive tract. Thus, awareness should be accompanied by the knowledge that normal endoscopy does not exclude a gastroenterological cause of NCCP in patients who also have confirmed CAD.

Twenty-four-hour oesophageal $\mathrm{pH}$-metry has been considered the most sensitive and specific test in the diagnosis of GERD and GER-related chest pain. Although $41-43 \%$ of patients with NCCP fulfilled the criteria for pathological GERD (Leise et al., 2010), a significant percentage of patients (about 25\%) in whom symptoms corresponded with heartburn had rather normal results for 24-hour $\mathrm{pH}$ monitoring examinations (Talaie et al., 2009). This discrepancy resulted from the method limitation, as 24-hour oesophageal $\mathrm{pH}$-metry detects acid reflux, and NCCP may also be provoked by the regurgitation of alkaline or neutral gastric content. Therefore, for NCCP diagnosis, especially in patients who are non-responsive to empirical therapy with PPIs, 24-hour simultaneous oesophageal impedance and $\mathrm{pH}$ monitoring seems to be more useful, mainly due to the possibility of non-acid gastrooesophageal reflux (GER) diagnosis (Sifrim \& Blondeau, 2006; Sifrim et al., 2009). An additional but practically the most valuable feature of this tool is the possibility of SI and SAP analysis. These enable the evaluation of the relationships between symptom occurrence and oesophageal function disorders which are not only related to the regurgitation of hydrochlorid acid. Only such a proven relationship gives an acceptable probability that oesophageal disorders are truly the reason for recurrent symptom episodes, and has been the basis of the identification of "GER-related" and "non-GER-related" chest pain (Dickman \& Fass, 2006; Fass \& Dickman, 2006; Fass \& Navarro-Rodriguez, 2008). One of the oldest tests estimating the 
associations between chest pain occurrence and oesophageal acidification is the Bernstein test. Recently, it has not been practically applied, but formerly it was widely used, not only as a diagnostic tool, but primarily in scientific investigation (Chauhan et al., 1996; Makk et al., 2000; Rosztóczy et al., 2007; Schofield et al., 1987, 1989).

Stationary oesophageal manometry, as well as recently introduced high resolution oesophageal manometry, has minor importance in NCCP diagnosis, mainly due to difficulties with confirming the association between chest pain episodes and motility disorders, and the still unsatisfactory treatment effects (Fass \& Dickman, 2006; Hershcovici \& Fass, 2010; Nam et al., 2006). However, 24-hour oesophageal function monitoring is potentially more useful, mainly due to the possibility of examining performance during patients' everyday activity, the greater probability of symptom occurrence during examination and the possibility of correlating their presence with oesophageal disorders (using an SI index or SAP). Moreover, there is now the opportunity to evaluate oesophageal $\mathrm{pH}$ and motility correlation on the basis of a greater number of analysed parameters in computer software. On the other hand, the usefulness of both oesophageal pH-metry, impedance examination and 24-hour oesophageal manometry is restricted to patients with daily, or at least every two days, symptom prevalence (Singh et al., 1992). Diagnosis of an NCCP source using 24-hour pH-metry or manometry has been obtained in $46 \%$ of patients in whom symptoms occurred at least once per day and only in $11 \%$ of subjects with chest pain of less frequency (Janssens et al., 1986). In the study by Eslick (2008), following examination of the most numerous population of patients with non-GER-related chest pain to have been assessed in this way, the distribution of oesophageal motility abnormalities was as follows: normal manometry in $70 \%$, nutcracker oesophagus $(14.4 \%)$, non-specific oesophageal motor disorder $(10.8 \%)$, diffuse oesophageal spasm $(3 \%)$, and other $(1,8 \%)$. In other papers, nutcracker oesophagus was the most prevalent oesophageal dysmotility in patients with chest pain (Fass \& Dickman, 2006; Fornari et al., 2008). Some authors have reported a greater prevalence of oesophageal motility disorders in patients admitted due to chest pain having a normal coronary angiogram than in patients with CAD (Adamek et al., 1999; Battaglia et al., 2005). Whereas, it has not only been my own experience, based on patients non-responsive to empirical therapy with PPIs, which has shown a similar frequency of oesophageal dysmotility in patients both with and without significant coronary artery narrowing (Budzyński, 2010b; Cooke et al., 1998).

As has been mentioned, the clinical usefulness of oesophageal motility examination does not seem to be of great value (Dickman \& Fass, 2006; Fass \& Dickman, 2006; Nam et al., 2006). Trials involving the provocative use of ergonovine, tensilon, bethanechol and pentagastrin, or oesophageal extension with a balloon have not improved diagnostic efficacy either. My own experience has shown the clinical usefulness of exercise-provoked oesophageal dysmotility diagnosis using simultaneous oesophageal manometry and ECG monitoring during a treadmill stress test. Some exercise-provoked oesophageal motility disorder appeared in $22 \%$ of patients with recurrent angina-like chest pain non-responsive to empirical therapy with PPIs (Budzyński et al., 2010; Budzyński, 2010a). The occurrence of angina-like chest pain, oesophageal acidification for more than $10 \mathrm{~s}$, and increased simultaneous contractions above $55 \%$ during a treadmill stress test had greater than $80 \%$ specificity for diagnosing GER-related and non-GER-related chest pain. The practical message coming from these observations was that patients with recurrent chest pain, who did not report e.g. chest pain during a treadmill stress test, have a low (20\%) probability of recognizing an oesophageal reason for their symptoms (Budzyński, 2010a). 
High frequency intraluminal ultrasound (HFIUS) is an available but rarely used examination, which makes it possible to assess the oesophageal muscle wall thickness in order to evaluate the longitudinal muscle contraction and oesophageal shortening in patients with oesophageal symptoms, including NCCP. Studies conducted using this technique suggest that prolonged oesophageal wall thickening can be connected with chest pain and heartburn episodes (Boesmans et al., 2010; Sifrim \& Blondeau, 2006; Sifrim et al., 2009). This examination has also helped to exclude oesophageal ischaemia from the mechanism of chest pain which is gastroenterological in origin (Hoff et al., 2010).

The possibility of having so many gastroenterological examinations for chest pain source diagnoses may lead to problems with making the correct choice. The practical diagnostic algorithm for NCCP presumed to be oesophageal in origin has been proposed by Fass and Navarro-Rodriguez (2008). In all patients with a suspected gastroenterological source of chest pain, after the exclusion of a cardiac origin, they suggest analysing the presence of alarm symptoms (e.g. fever, stomach pain at night, weight loss, anaemia, and signs of bleeding from the digestive tract). If any of these is present, a panendoscopy should first be conducted and treatment should be chosen depending on the diagnosis. In patients without alarm signs, symptom evaluation and testing with PPIs was proposed as the first diagnostic step. In responders to empirical therapy, PPIs should be continued. In patients who fail this test, oesophageal pH-metry "on-therapy", manometry and other gastroenterological investigations, including psychiatric assessment, should be considered.

Careful application of this algorithm in patients with CAD is justified by the proven overlapping of oesophageal chest pain sources in about $30-46 \%$ of patients with CAD and cardiac syndrome X (Budzyński et al., 2008; Dobrzycki et al., 2005; Hewson et al., 1990; Oranu \& Vaezi, 2010; Singh et al., 1992). Moreover, about $20 \%$ of all myocardial ischaemia episodes in patients with CAD correlated with pathological acid gastro-oesophageal reflux episodes, and were recognized as reflexive myocardial silent ischaemia or ischaemic cardiac chest pain due to cardio-oesophageal reflex activation (Dobrzycki et al., 2005). In light of these neurally-mediated cardio- oesophageal interrelationships, a comparison of the coronary reserve in a non-invasive evaluation before and after empirical therapy with PPIs seems to be worth recommending in stable CAD patients, before the next coronarography performance. A decrease in the signs of myocardial ischaemia after one- or two-week-long therapies with PPIs may help to recognize exacerbation of myocardial ischaemia due to oesophageal chemo- receptor activation, which is possible in about half of patients with CAD or cardiac syndrome X (Budzyński et al., 2008; Chauhan et al, 1996; Rosztóczy et al., 2007; Świątkowski et al., 2004). In non-responders to PPI therapy, similarly to patients with NCCP, endoscopy, oesophageal impedance with pH-metry, oesophageal manometry with or without exercise provocation, as well as psychiatric examination, might be helpful (Fass \& Navarro- Rodrigues, 2008; Katerndahl, 2004).

\section{Treatment}

Once the accurate diagnosis of the source of angina-like chest pain has been established, a specific therapy should be recommended. If recurrent chest pain originates only from the heart, due to either ischaemic cardiac or non-ischaemic cardiac disease, typical anti-angina pharmacotherapy and/or myocardial revascularization should be recommended, taking into account the results of the Clinical Outcomes Utilizing Revascularization and Aggressive Drug Evaluation (COURAGE) trial. In patients with refractory angina diagnosed as cardiac 
in origin, a number of methods have been proposed (Kones, 2010). They are as follows: percutaneous myocardial laser revascularization (PMLR) (McGillion et al., 2010); spinal cord stimulation (SCS) (Lanza et al., 2011); enhanced external counterpulsation (EECP); percutaneous application of low frequency ultrasound, i.e. mechanical shock waves with ECG gating; angiogenesis stimulation by the VEGF gene and CD34+ stem cell therapy; etc. Individuals with angina-like chest pain with normal coronary angiogram and patients with $\mathrm{CAD}$ and overlapping gastroenterological symptoms may achieve symptomatic improvement after therapy oriented to oesophageal disorders (Phan et al., 2009). Such therapy may consist of long-term treatment with PPIs, therapy with calcium antagonists (Budzyński, 2010a; Budzyński et al., 2010), Helicobacter pylori eradication (Budzyński, 2011), as well as tricyclic antidepressants (Eslick, 2008; Fass, 2008; Fass \& Navarro-Rodriguez, 2008), selective serotonin reuptake inhibitors (citalopram, sertaline) or trazodone (Broekaert et al., 2006). Recent studies have also indicated the favourable effect of theophylline (Rao et al., 2007), botulinum toxin (Achem, 2008; Fass \& Navarro-Rodriguez, 2008), acupuncture (Dickman et al., 2007b; Macpherson and Dumville, 2007; Pfab et al., 2011), melatonin due to its positive cardiological and gastroenterological action (Dominiguez-Rodriguez et al., 2009; Konturek et al., 2008; Pereira, 2006), hypnotherapy (Jones et al., 2006; Palsson and Whitehead, 2006), transcutaneous electrical nerve stimulation (TENS) (Borjesson et al., 1998), oesophageal dilatation, oesophagomyotomy and Nissen fundoplication (Achem, 2008; Dickman \& Fass, 2006; Phan et al., 2009).

The outcome of long-term therapy with PPIs in patients with NCCP has been widely studied (Bautista et al, 2004; Cremonini et al., 2005, 2010; Dickman et al., 2005; Dickman \& Fass, 2006; Liuzzo et al., 2005; Wang et al, 2005). These drugs have shown a favourable effect in $80 \%$ of patients with "GER-related" chest pain (Dickman \& Fass, 2006). The relative risk reduction for continued chest pain after PPI therapy was 0.54 (95\% CI, 0.41-0.71), with an NNT amounting to 3 (Cremonini et al., 2005). The recent meta-analysis by Cremonini et al. (2010) has also shown an advantage with therapy using a PPI over a placebo with an odds ratio of 3.75 (95\% CI, 2.78-4.96), as well as a high placebo response amounting to $18.85 \%$ (range $2.94 \%-47.06 \%$ ). Successful therapy with PPIs is most likely in patients with a GERD diagnosis (Gąsiorowska et al., 2009; Oranu \& Vaezi, 2010; Seo et al., 2010). Among these subjects, acid exposure time (AET), symptom association probability (SAP), and the symptom index (SI) obtained from 24-hour oesophageal $\mathrm{pH}$-metry or 24-hour oesophageal impedance with $\mathrm{pH}$ analysis are considered the predictors of a favourable therapeutic outcome (Kushnir et al., 2010).

Until now, there have only been a few works evaluating the role of therapy with PPIs in patients with CAD and recurrent chest pain suspected to be non-cardiac in origin and overlapping ischaemic, cardiac-derived chest pain (Budzyński et al., 2008; Dobrzycki et al., 2005; Liuzzo et al., 2005; Mehta et al., 1996; Świątkowski et al., 2004). All of them, including our own work, have evidenced a decrease in chest pain severity and amelioration in healthrelated quality of life estimated using the SF-36 survey, as well as an improvement in ECG signs of myocardial ischaemia, both during a treadmill stress test (a reduction in subject percentage with a significant decrease in ST interval during the stress test) and during 24hour ECG Holter monitoring (a decrease in the number of ST-segment depression episodes and total duration of ischaemic episodes-total ischaemic burden) after therapy with PPIs. Liuzzo et al. (2005), studying a veteran patient population with documented CAD, showed through multivariate analysis and proton pump inhibitor therapy that they could independently predict a significant reduction in the prevalence of patients experiencing 
chest pain ( $\mathrm{OR}=0.09)$, emergency department visits $(\mathrm{OR}=0.15)$, and hospitalization $(\mathrm{OR}=$ 0.14 ) for chest pain. On the other hand, our own results have shown that the mentioned favourable PPI effect on the angina pectoris course in patients with CAD should be carefully interpreted because it might not only result from the decrease in cardio-oesophageal reflex activation and therapy with aspirin-induced gastropathy, but also from the increase in nitric oxide bioavailability observed after therapy with rabeprazole in an open-label trial (Kłopocka et al., 2006), as well as the increase in the beta-endorphin plasma level revealed for omeprazole in a randomized, double-blind, placebo-controlled, crossover study (Budzyński et al., 2010).

As has been mentioned, besides a decrease in oesophageal acid exposure time and a reduction in GER-related myocardial ischaemic episodes, PPIs may also improve the course of angina-like chest pain by the alleviation of symptoms related to gastric disease (gastric and duodenal ulcer disease), by preventing and treating aspirin-induced gastropathy, as well as by reducing the risk of haemorrhagic complications from the upper part of the digestive tract and the prevention of secondary anaemia (ACCF, 2010; Bhatt et al., 2008; Hsiao et al., 2009). Tailored PPI prescription should prevail over the generalized in their recommendation for use with patients on dual anti-platelet therapy because of reported and still not definitely excluded potentially life-threatening interactions between PPIs and antiplatelet drugs (clopidogrel, aspirin). Pantoprazole or esomeprazole should be chosen for gastroprotection or time intervals between respective medicines should be recommended (ACCF, 2010; Bhatt et al., 2008). The easiest method for the last option is the recommendation of PPIs in the morning and clopidogrel in the evening.

In patients with recurrent chest pain and GERD diagnosed using oesophageal $\mathrm{pH} /$ impedance monitoring and non-responsive to PPIs, many other kinds of therapy have been proposed, including the following: doubling the PPI dose, switching to another PPI, adding histamine type 2-receptor antagonists at night, baclofen recommendation, as well as laparoscopic or open surgery (Dickman \& Fass, 2006; Hershcovici \& Fass, 2010; Kushnir et al, 2010; Oranu \& Vaezi, 2010; Labenz, 2010). The exclusion of eosinophilic oesophagitis in patients with NCCP and aged under 45, atopy or dysphagia might also be helpful (GarciaCompeăn et al., 2011). Dickman et al. (2007b) found acupuncture added to a single dose of PPI to be more effective than doubling the proton pump inhibitor dose in controlling GERDrelated symptoms in patients who had failed with standard dose proton pump inhibitors.

Calcium antagonists, such as verapamil, diltiazem, nifedipine and amlodipine, have mainly been used in therapy for NCCP due to hypertensive oesophageal motility disorders diagnosed using stationary manometry (Dickman \& Fass, 2006; Fass \& Navarro-Rodriguez, 2006). The reported effects of these drugs in patients with recurrent angina-like chest pain were ambiguous. Some studies have shown a favourable outcome for this group of drugs, some have not confirmed it (Dickman \& Fass, 2006; Eslick et al., 2005; Eslick, 2008; Fass \& Dickman, 2006). Our own, recently published investigation has shown that patients with recurrent angina-like chest pain non-responsive to treatment with PPIs and an established diagnosis of exercise-provoked oesophageal spasm (EPOS), for whom a calcium antagonist was recommended due to exercise-provoked oesophageal spasm, had a significantly lower risk of hospitalization due to suspected acute coronary syndrome in the 2.7-year follow-up period than the remaining patients $(\mathrm{NNT}=3.5)$ (Budzyński et al., 2010). In my own work it has been documented that $\mathrm{Hp}$ eradication had a similar favourable outcome (NNT = 2.7) (Budzyński, 2011). The rationales behind this therapy were the above-cited role of this infection in chest pain pathogenesis both cardiac and gastroenterological in origin. 
Psychiatric disorders and anxiety focusing on the heart are common in patients with NCCP (Achem, 2008; Dickmann \& Fass, 2006; Fass \& Navarro-Rodriguez, 2008; Katerndahl, 2004). They may act as individual factors or via the increase in visceral hypersensitivity. Some studies have shown oesophageal motility abnormalities as markers of depressive or panic disorders. The last were found in $80 \%$ of patients with NCCP and oesophageal motor dysfunction and in $30 \%$ of subjects with a normal coronary angiogram and oesophageal examinations (Dickman \& Fass, 2006). Eslick et al. (2005) have even recommended empirical therapy with tricyclic antidepressants in patients with recurrent chest pain non-responsive to PPIs. The rationale behind such a recommendation is that antidepressants act as pain modulators. In patients with NCCP, behaviour therapy involving trazodone, imipramine, amitriptyline, nortriptyline, citalopram, desipramine and sertraline was used for this purpose (Broekaert et al., 2006; Eslick, 2008; Fass, 2008; Fass \& Navarro-Rodriguez, 2008). Their clinical efficacy was confirmed both in uncontrolled and in randomized, placebocontrolled trials. However, the prescribing of these drugs should always be carried out carefully, because of the potential cardiovascular risk of tricyclic antidepressants connected with their adverse effects, such as prolonged QT intervals, hypertension, postural hypotension, and effects on heart rate variability (Hamer et al., 2011). Probably because of this, non-pharmacological methods which could potentially be efficient in subjects with NCCP have been investigated, such as hypnotherapy, behaviour therapy, and acupuncture (Dickman et al., 2007b; Pfab et al., 2011; Yin and Chen, 2010; Zhang et al., 2010). Acupuncture has had a favourable effect on gastric emptying, oesophageal motility, and in patients with GERD, a potential substrate of non-cardiac chest pain. In the study by Macpherson and Dumville (2007), 42\% of the patients investigated with a diagnosis of NCCP made in a Rapid Access Chest Pain Unit reported that they would consider acupuncture, $36 \%$ reported that they would not, and $22 \%$ did not know. Moreover, in the pilot study by Gąsiorowska et al. (2009), a favourable effect of 18 Johrei sessions (a kind of meditation) during six weeks in comparison to waiting-list control patients with functional chest pain was found. The clinical outcome of the mentioned methods is, among other things, explained by a decrease in visceral hypersensitivity, for which one of the mediators may be endogenous opioids, one of the potential pathways of the effect of PPIs (Budzyński et al., 2010). However, it should be checked for each patient as to whether his or her panic or depressive symptoms are the true cause of chest pain recurrence or its cofactor, and not an effect of symptom duration chronicity and the lack of an appropriate diagnosis.

However, particularly in populations with high cardiovascular risk, the appropriate control of cardiovascular risk factors is very important in therapy for patients with angina-like chest pain. The recent study by Leise et al. (2010) has shown that patients with recurrent anginalike chest pain which is gastroenterological but unknown in origin (NCCP-U), in spite of generally being considered as having low cardiac morbidity and mortality, may ultimately show a higher cardiovascular and non-cardiovascular death risk. In this analysis, whose results should still be interpreted with limitations, the NCCP group with a diagnosis of gastrointestinal disorder displayed less overall survival at all time points, specifically $70.1 \%$ at 10 years and $51.8 \%$ at 20 years, compared with their NCCP-U counterparts. The independent death risk factors in adjusted univariate analysis using Cox's proportional hazards model were as follows: age, the Charlson comorbidity index, previous CABG, and previous valvular disease. No specific cardiac or gastroenterological tests or their absence was associated with mortality. The authors explain their observations by the effect of the coexistence of gastroenterological disorders with latent non-ischaemic cardiovascular 
disease, coronary artery spasm (Charng et al., 1988; Makk et al., 2000; Manfrini et al., 2006; Rasmussen et al., 1986), microvascular disease (cardiac syndrome X) or at least endothelial dysfunction. An important aspect might also be an overlapping of risk factors for both systems' diseases, such as obesity, obstructive sleep apnoea, hypertension, smoking, and diabetes mellitus.

On the other hand, the study by Leise et al. (2010) has also shown that proper management of patients with recurrent chest pain which is extracardiac in origin is still a great challenge for physicians. During a 20-year follow-up period since an initial visit to an emergency department due to a recurrent chest pain experience, $49 \%$ of patients sought subsequent care from the emergency department, $42 \%$ had repeated cardiology evaluations, and only $15 \%$ were seen by a gastroenterologist. Thirty-eight percent underwent oesophagogastroduodenoscopy, but very few underwent manometry or a $\mathrm{pH}$ probe.

\section{Study limitations}

The main limitations concerning investigations on the pathogenesis, diagnosis and treatment for patients with recurrent angina-like chest pain, both in patients with and without significant coronary artery narrowing, have been the small number of subject groups, which on average included a little over 100 participants. Only in three studies were the subject groups larger. The other limitations have involved the lack of or a short followup period, recommendations of different medication and their doses, non-homogeneous definitions of oesophageal disorders, the establishment of different study endpoints, and only single-centre experience presentations.

\section{Future research}

Further studies should validate the test of empirical therapy with PPIs in patients with CAD. It would also be significant if the mechanisms for the visceral hypersensitivity leading to a decrease in the chest pain threshold could be identified. The evaluation of some new diagnostic methods, including analysis for cerebral evoked potentials, would also be useful. Moreover, it seems to be important to check once more and re-evaluate the appropriate indications for coronary angiography, both because of its costs and its inseparable exposure to procedure-connected health risks and substantial radiation. All the recommended examinations, both cardiological and gastroenterological, should be connected with precise investigations into cardio-oesophageal and other vagally-mediated reflexes and on the determination of factors predicting their clinical importance. New therapeutic methods for recurrent angina-like non-cardiac chest pain should also be investigated, although critical analysis of relationships between benefits and costs should be performed.

\section{Conclusions}

- Angina-like chest pain is a common problem in health care because of its prevalence, diagnostic difficulties, resource utilization and potential connection with a reduced health-related quality of life and shorter survival times. This symptom is conditioned by biological, psychological and social factors.

- Angina pectoris may be caused by diseases of the cardiovascular system, digestive tract, and other extracardiac disorders which lead to an imbalance between myocardial blood 
supply and oxygen requirement (e.g. anaemia or thyrotoxicosis). In respective patients, potential chest pain causes may overlap and influence each other. Therefore, NCCP may be present in patients both with and without heart diseases. However, the main and first purpose of its diagnostic procedures should be to exclude potentially lifethreatening origins.

- Digestive tract diseases may cause angina-like chest pain along at least three pathways. Chest pain may originate from: (1) the oesophagus, stomach or gall bladder, due to stimulation of their chemo-, mechano-, and/or thermoreceptors; (2) the heart due to activation of cardio-oesophageal neural reflexes and secondary diminished myocardial perfusion; as well as (3) the heart due to a decrease in myocardial oxygen supply in the course of anaemia, secondary to acute or chronic alimentary tract bleeding, malabsorption, maldigestion, blood sequestration or autoimmunological reactions. Helicobacter pylori infection may play a role in all of these mechanisms.

- The misdiagnosis of cardio-oesophageal interrelationships may lead to the progressive acceleration of the course of the disorders of both systems and the intensity of their symptoms. This occurs in at least three vicious circle mechanisms: neural, inflammatory (neuro-immune crosstalk), and the haemorrhagic complications of anti-thrombotic drugs expressed as anaemia.

- The most frequent causes of NCCP are as follows: GERD, oesophageal motility disorders and panic abnormalities. Their diagnosis needs many times to use more advanced and more specialized diagnostic methods than panendoscopy, such as oesophageal impedance, $\mathrm{pH}$-metry, manometry, or endosonography.

- In the diagnosis of recurrent chest pain of possible oesophageal origin, the most important factor is to confirm the relationship between chest pain episode occurrence and oesophageal disorders. Such a possibility is provided by the test of empirical therapy using PPIs (the "omeprazole test") and, in non-responsive cases, 24-hour oesophageal $\mathrm{pH}$-metry, impedance or manometry with SI or SAP analysis. These help to recognize the source of chest pain in $40-80 \%$ of patients.

- The usefulness of exercise-provoked oesophageal disorders, such as exercise-provoked gastro-oesophageal reflux or oesophageal spasm, needs to be evaluated. Any further investigations need also to estimate the interrelationships between the course of cardiovascular and gastroenterological tests as predictors of false positives in their outcomes.

- Therapy for recurrent, angina-like chest pain should be based on the detailed diagnosis of its origin (whether cardiac or extracardiac), an assessment of its possible influence on myocardial perfusion, and the control of cardiovascular risk factors.

- Modern cardiac and gastrointestinal diagnostic methods would probably help to better recognize NCCP pathophysiology, facilitating its diagnosis and treatment. However, they will need to be critically evaluated, not only in relation to potential clinical usefulness, but also in accordance with risk-benefit and benefit-cost ratios.

\section{References}

Achem, SR. (2008) Noncardiac chest pain-treatment approaches. Gastroenterology Clinics of North America, Vol.37, No.4, (December, 2008), pp.859-78, ISSN 0889-8553 
Adamek, RJ., Bock, S., \& Pfaffenbach, B. (1998a) Oesophageal motility patterns and arterial blood pressure in patients with chest pain and normal coronary angiogram. European Journal of Gastroenterology and Hepatology, Vol.10, No.11, (November 1998), pp. 941-5, ISSN 0954-691X

Adamek, RJ., Bock, S., Szymanski, C., Hagemann, D., \& Pfaffenbach B. (1998b) Increased occurrence of esophageal hypermotility disorders in patients with arterial hypertension. Deutsche Medizinische Wochenschrift, Vol.123, No.12, (March 1998), pp.341-6, ISSN 0012-0472

Adamek, RJ., Roth, B., Zymanski, CH., Hagemann, D., \& Pfaffenbach, B. (1999) Esophageal motility patterns in patients with and without coronary heart disease and healthy controls. Hepatogastroenterology, Vol.46, No.27, (May-Juni 1999), pp.1759-64, ISSN 0172-6390

Adamopoulos, AB., Sakizlis, GN., Nasothimiou, EG., Anastasopoulou, I., Anastasakou, E., \& Kotsi P. (2009) Do proton pump inhibitors attenuate the effect of aspirin on platelet aggregation? A randomized crossover study. Journal of Cardiovascular Pharmacology, Vol.54, No.2, (August 2009), pp.163-8, ISSN 0160-2446

American College of Cardiology Foundation (ACCF) Task Force on Expert Consensus Documents, Abraham, N.S., Hlatky, M.A., Antman, EM., Bhatt, DL., Bjorkman, DJ., Clark, CB., Furberg, CD., Johnson, DA., Kahi, CJ., Laine, L., Mahaffey, KW., Quigley, EM., Scheiman, J., Sperling, LS., \& Tomaselli, GF. (2010) ACCF/ACG/AHA 2010 Expert Consensus Document on the Concomitant Use of Proton Pump Inhibitors and Thienopyridines. A Focused Update of the ACCF/ACG/AHA 2008 Expert Consensus Document on Reducing the Gastrointestinal Risks of Antiplatelet Therapy and NSAID Use. Journal of American College of Cardiology, Vol.56, No.24, (December 2010), pp.2051-2066, ISSN 0735-1097

American Society for Gastrointestinal Endoscopy (ASGE) Standards of Practice Committee, Anderson, MA., Ben-Menachem, T., Gan, SI., Appalaneni, V., Banerjee, S., Cash, BD., Fisher, L., Harrison, ME., Fanelli, RD., Fukami, N., Ikenberry, SO., Jain, R., Khan, K., Krinsky, ML., Lichtenstein, DR., Maple, JT., Shen, B., Strohmeyer, L., Baron, T., \& Dominitz, JA. (2009) Management of antithrombotic agents for endoscopic procedures. Gastrointestinal Endoscopy, Vol.70, No.6, (December 2009),pp.1060-70, ISSN 0016-5107

Battaglia, E., Bassotti, G., Buonafede, G., Serra, AM., Dughera, L., Orzan, F., Casoni, R., Chistolini, F., Morelli, A., \& Emanuelli, G. (2005) Noncardiac chest pain of esophageal origin in patients with and without coronary artery disease. Hepatogastroenterology, Vol.52, No.63, (May- Juni 2005), pp.792-795, ISSN 0172-6390

Bautista, J., Fullerton, H., Briseno, M., Cui, H., \& Fass, R. (2004) The effect of an empirical trial of high-dose lansoprazole on symptom response of patients with non-cardiac chest pain--a randomized, double-blind, placebo-controlled, crossover trial. Alimentary Pharmacology and Therapeutics, Vol.19, No.10, (May 2004), pp.1123-30, ISSN 0269-2813

Bhatt, DL., Scheiman, J., Abraham, NS., Antman, EM., Chan, FK., Furberg, CD., Johnson, DA., Mahaffey, KW., Quigley, EM., Harrington, RA., Bates, ER., Bridges, CR., Eisenberg, MJ., Ferrari, VA., Hlatky, MA., Kaul, S., Lindner, JR., Moliterno, DJ., 
Mukherjee, D., Schofield, RS., Rosenson, RS., Stein, JH., Weitz, HH., Wesley, DJ., \& American College of Cardiology Foundation Task Force on Clinical Expert Consensus Documents. (2008) ACCF/ACG/AHA 2008 expert consensus document on reducing the gastrointestinal risks of antiplatelet therapy and NSAID use: a report of the American College of Cardiology Foundation Task Force on Clinical Expert Consensus Documents. Journal of American College Cardiology, Vol.52, No.18, (October 2008), pp.1502-17, ISSN 0735-1097

Boesmans, W., Vanden Berghe, P., Farre, R., \& Sifrim, D. (2010) Oesophageal shortening: in vivo validation of high-frequency ultrasound measurements of oesophageal muscle wall thickness. Gut, Vol.59, No.4, (April 2010), pp.433-40, ISSN 0017-5749

Borjesson, M., Pilhall, M., Eliasson, T., Norssell, H., Mannheimer, C., \& Rolny, P. (1998) Esophageal visceral pain sensitivity: effects of TENS and correlation with manometric findings. Digestive Disease and Sciences, Vol.43, No.8, (August 1998), pp.1621-8, ISSN 0163-2116

Broekaert, D., Fischler, B., Sifrim, D., Janssens, J., \& Tack, J. (2006) Influence of citalopram, a selective serotonin reuptake inhibitor, on oesophageal hypersensitivity: a doubleblind, placebo-controlled study. Alimentary Pharmacology and Therapeutics, Vol.23, No.3, (February 2006), pp.365-70. ISSN 0269-2813

Budzyński, J., Kłopocka, M., Bujak, R., Świątkowski, M. \& Sinkiewicz W. (2004) Autonomic nervous function in Helicobacter pylori infected patients with atypical chest pain studied by analysis of heart rate variability. European Journal of Gastroenterology and Hepatology,Vol.16, No.5, (May 2004), pp.451-7, ISSN 0954-691X

Budzyński, J., Kłopocka, M., Pulkowski, G., Suppan, K., Fabisiak, J., Majer, M., \& Świątkowski, M. (2008) The effect of double dose of omeprazole on the course of angina pectoris and treadmill stress test in patients with coronary artery disease- a randomised, double-blind, placebo controlled, crossover trial. International Journal of Cardiology, Vol.127, No.2, (July 2008), pp.233-239, ISSN 0167-5273

Budzyński, J. \& Pulkowski, G. (2009) [Atrial fibrillation, the other arrhythmias and digestive tract.] Kardiologia Polska Vol.67, No.11, (November 2009), pp.1268-1273, ISSN 00229032

Budzyński, J., Pulkowski, G., Kłopocka, M., Augustyńska, B., Sinkiewicz, A., Suppan, K., Fabisiak, J., Majer, M., \& Świątkowski M (2010) The treatment with double dose of omeprazole increases in beta-endorphin plasma level in patients with coronary artery disease. Archives of Medical Sciences, Vol.6, No.2, (April 2010), pp.201-207, ISSN 1734-1922

Budzyński, J. (2010a) Exercise-provoked esophageal motility disorder in patients with recurrent chest pain. World Journal of Gastroenterology,Vol.16, No.35, (September 2010), pp.4428-35 ISSN 1007-9327

Budzyński J. (2010b) Exertional esophageal pH-metry and manometry in recurrent chest pain. World Journal of Gastroenterology,Vol.16, No.34, (September 2010), pp.4305-12, ISSN 1007-9327

Budzyński, J. (2010c) Does esophageal dysfunction affect the course of treadmill stress tests in patients with recurrent angina-like chest pain? Polskie Archiwum Medycyny 
Wewnętrznej (Polish Archives of Internal Medicine), Vol.120, No.12, (December 2010), pp.484-489, ISSN 0032-3772

Budzyński, J. (2011) The favorable effect of Helicobacter pylori eradicative therapy in patients with recurrent angina-like chest pain and non-responsive to proton pump inhibitors: a preliminary study. Archives of Medical Science, Vol.7, No.1, (January 2011), pp.73-80, ISSN 1734-1922

Bugiardini, R., Bairey- Merz, CN. (2005) Angina with 'normal' coronary arteries: a changing philosophy. JAMA: The Journal of American Medical Association. Vol.293, No.4, (January 2005), pp.477-84, ISSN 0098-7484

Bunch, TJ., Day, JD., Anderson, JL., Horne, BD., Muhlestein, JB., Crandall, BG., Weiss, JP., Lappe, DL. \& Asirvatham, SJ. (2008a) Frequency of Helicobacter pylori seropositivity and C-reactive protein increase in atrial fibrillation in patients undergoing coronary angiography. American Journal of Cardiology, Vol.101, No.6, (March 2008), pp.848-51, ISSN 0002-9149

Bunch, TJ, Packer, DL, Jahangir, A., Locke, GR., Talley, NJ., Gersh, BJ., Roy, RR., Hodge, DO. \& Asirvatham SJ. (2008b) Long-term risk of atrial fibrillation with symptomatic gastroesophageal reflux disease and esophagitis. American Journal of Cardiology, Vol.102, No.9, (August 2008), pp.1207-11, ISSN 0002-9149

Caldwell, MT., Byrne, PJ., Marks, P., Walsh, TN. \& Hennessy TP. (1994) Bradykinin, coronary artery disease and gastro-oesophageal reflux. British Journal of Surgery, Vol.81, No.10, (October 1994), pp.1462-4, ISSN 0007-1323

Cayley, WE Jr. (2005) Diagnosing the cause of chest pain. American Family Physician, Vol.72, No.10, (November 2005), pp.2012-21, ISSN 0002-838X

Celik, T, Iyisoy, A. \& Yuksel, UC. (2010) Possible pathogenetic role of Helicobacter pylori infection in cardiac syndrome X. International Journal of Cardiology, Vol.142, No.2, (July 2010), pp.193-4, ISSN 0167-5273

Charng, MJ., Wang, SP., Chang, MS. \& Chiang, BN. (1988) Coronary spasm complicating sclerotherapy of esophageal varices. Chest. Vol.93, No.1, (January 1988), pp.204-5, ISSN 0012-3692

Chauhan, A., Petch, MC. \& Schofield, PM. (1996) Cardio-oesophageal reflex in humans as a mechanism for "linked angina". European Heart Journal, Vol.17, No.3, (March 1996), pp.407-413 ISSN 0195-668X

Cheung, TK., Hou, X., Lam, KF., Chen, J., Wong, WM., Cha, H., Xia, HH., Chan, AO., Tong, TS., Leung, GY., Yuen, MF. \& Wong, BC. (2009) Quality of life and psychological impact in patients with noncardiac chest pain. Journal of Clinical Gastroenterology, Vol.43, No.1, (January 2009), pp.13-8, ISSN 0192-0790

Collins, SM., Denou, E., Verdu, EF. \& Bercik P. (2009) The putative role of the intestinal microbiota in the irritable bowel syndrome. Digestive and Liver Diseases. Vol.41, No.12, (December 2009), pp.850-3, ISSN 1590-8658

Cooke, RA., Anggiansah, A., Chambers, JB. \& Owen WJ. (1998) A prospective study of oesophageal function in patients with normal coronary angiograms and controls with angina. Gut, Vol.42, No.3, (March 1998), pp.323-9, ISSN 0017-5749 
Cremonini, F., Wise, J., Moayyedi, P. \& Talley, NJ. (2005) Diagnostic and therapeutic use of proton pump inhibitors in non-cardiac chest pain: a metaanalysis. The American Journal of Gastroenterology, Vol.100, No.6, (Juni 2005), pp.1226-32, ISSN 0002-9270

Cremonini, F., Ziogas, DC., Chang, HY., Kokkotou, E., Kelley, JM., Conboy, L., Kaptchuk, TJ. \& Lembo, AJ. (2010) Meta-analysis: the effects of placebo treatment on gastrooesophageal reflux disease. Alimentary Pharmacology and Therapeutics, Vol.32, No.1, (July 2010), pp.29-42, ISSN 0269-2813

Cubattoli, L., Barneschi, C., Mastrocinque, E., Bonucci, P. \& Giomarelli, PP. (2009) Cardiac arrest after intragastric balloon insertion in a super-obese patient. Obesity Surgery, Vol.19, No.2, (February 2009), pp.253-6, ISSN 0960-8923

Cuomo, R., De Giorgi, F., Adinolfi, L., Sarnelli, G., Loffredo, F., Efficie, E., Verde, C., Savarese, MF., Usai, P. \& Budillon, G. (2006) Oesophageal acid exposure and altered neurocardiac function in patients with GERD and idiopathic cardiac dysrhythmias, Alimentary Pharmacology and Therapeutics. Vol.24, No.2, (July 2006), pp.361-70, ISSN 0269-2813

Dai, X., Makaryus, AN., Makaryus, JN. \& Jauhar, R. (2009) Significant gastrointestinal bleeding in patients at risk of coronary stent thrombosis. Reviews in cardiovascular medicine, Vol.10, No.1, (Winter 2009), pp.14-24, ISSN 1530-6550

de Aquino Lima, JP. \& Brophy, JM. (2010) The potential interaction between clopidogrel and proton pump inhibitors: A systematic review. BMC Medicine, Vol.8, No.1, (December 2010), pp.81, ISSN 1741-7015

Dickman, R., Emmons, S., Cui, H., Sewell, J., Hernández, D., Esquivel, RF. \& Fass, R. (2005) The effect of a therapeutic trial of high-dose rabeprazole on symptom response of patients with non-cardiac chest pain: a randomized, double-blind, placebocontrolled, crossover trial. Alimentary Pharmacology and Therapeutics, Vol.22, No.6, (September 2005), pp.547-55. ISSN 0269-2813

Dickman, R. \& Fass, R. (2006) Noncardiac chest pain. Clinical gastroenterology and hepatology : the official clinical practice journal of the American Gastroenterological Association, Vol.4, No.5, (May 2006), pp.558-63, ISSN 1542-3565

Dickman, R., Mattek, N., Holub, J., Peters, D. \& Fass R. (2007a) Prevalence of upper gastrointestinal tract findings in patients with noncardiac chest pain versus those with gastroesophageal reflux disease (GERD)-related symptoms: results from a national endoscopic database. The American Journal of Gastroenterology, Vol.102, No.6, (June 2007), pp.1173-9, ISSN 0002-9270

Dickman, R., Schiff, E., Holland, A., Wright, C., Sarela, SR., Han, B. \& Fass R. (2007b) Clinical trial: acupuncture vs. doubling the proton pump inhibitor dose in refractory heartburn. Alimentary Pharmacology and Therapeutics, Vol.26, No.10, (November 2007), pp.1333-44, ISSN 0269-2813

Dobrzycki, S., Baniukiewicz, A., Korecki, J., Skrodzka, D., Prokopczuk, P., ZarembaWoroniecka, A., Żuk, J. \& Łaszewicz, W. (2005) Does gastro-esophageal reflux provoke myocardial ischemia in patients with CAD? International Journal of Cardiology, Vol.104, No.1, (September 2005), pp.67-72, ISSN 0167-5273 
Dominguez-Rodriguez, A., Abreu-Gonzalez, P. \& Reiter, RJ. (2009) Clinical aspects of melatonin in the acute coronary syndrome. Current Vascular Pharmacology, Vol.7, No.3, (July 2009), pp.367-73, ISSN 1570-1611

Drewes, AM., Arendt-Nielsen, L., Funch-Jensen, P. \& Gregersen, H. (2006) Experimental human pain models in gastro-esophageal reflux disease and unexplained chest pain. World Journal of Gastroenterology, Vol.12, No.12, (May 2006), pp.2806-17, ISSN 1007-9327

Drossman, DA. (2006) The Functional Gastrointestinal Disorders \& the Rome III Process. Gastroenterology, Vol.130, No.5, (April 2006), pp.1377-1390, ISSN 0016-5085

Duygu, H., Ozerkan, F., Saygi, S. \& Akyüz, S. (2008) Persistent atrial fibrillation associated with gastroesophageal reflux accompanied by hiatal hernia. The Anatolian Journal of Cardiology. Vol.8, No.2, (April 2008), pp.164-5, ISSN 1302-8723

Erhardt, L., Herlitz, J., Bossaert, L., Halinen, M., Keltai, M., Koster, R., Marcassa, C., Quinn, T., van Weert, H. \& Task Force on the management of chest pain. (2002) Task force on the management of chest pain. European Heart Journal, Vol.23, No.15, (August 2002), pp.1153-76, ISSN 0195-668X

Eskandarian, R., Malek, M., Mousavi, SH. \& Babaei, M. (2006) Association of Helicobacter pylori infection with cardiac syndrome X. Singapore Medical Journal, Vol.47; No.8, (August 2006), pp.704-6, ISSN 0037-5675

Eslick, GD., Coulshed, DS., \& Talley, NJ. (2005) Diagnosis and treatment of noncardiac chest pain. Nature clinical practice. Gastroenterology and Hepatology. Vol.2, No.10, (October 2005), pp.463-72, ISSN 1743-4378

Eslick, GD, \& Talley NJ. (2004) Non-cardiac chest pain: predictors of health care seeking, the types of health care professional consulted, work absenteeism and interruption of daily activities. Alimentary Pharmacology and Therapeutics, Vol.20, No.8, (October 2004), pp.909-15, ISSN 0269-2813

Eslick, GD. (2008) Classification, natural history, epidemiology, and risk factors of noncardiac chest pain. Disease a Month, Vol.54, No.9, (September 2008), pp.593-603, ISSN 0011-5029

Fass, R. \& Dickman, R. (2006) Non-cardiac chest pain: an update. Neurogastroenterology and Motility, Vol.18, No.6, (June 2006), pp.408-17, ISSN 1350-1925

Fass, R. \& Navarro-Rodriguez, T. (2008) Noncardiac chest pain. Journal of Clinical Gastroenterology, Vol.42, No.5, (May- June 2008), pp.636-46, ISSN 0192-0790

Fass, R. (2008) Evaluation and diagnosis of noncardiac chest pain. Disease- $a$ - Month, Vol.54, No.9, (September 2008), pp.627-41, ISSN 0011-5029

Fornari, F., Farré, R., van Malenstein, H., Blondeau, K., Callegari-Jacques, SM. \& Barros, SG. (2008) Nutcracker oesophagus: association with chest pain and dysphagia controlling for gastro- oesophageal reflux. Digestive and Liver Diseases, Vol.40, No.9, (September 2008), pp.717-22. ISSN 1590-8658

Fox, KF. (2005) Investigation and management of chest pain. Heart (British Cardiac Society), Vol.91, No.1, (January 2005), pp.105-10, ISSN 1355-6037

Franceschi, F., Niccoli, G., Ferrante, G., Gasbarrini, A., Baldi, A., Candelli, M., Feroce, F., Saulnier, N., Conte, M., Roccarina, D., Lanza, GA., Gasbarrini, G., Gentiloni, SN. \& Crea F. (2009) CagA antigen of Helicobacter pylori and coronary instability: insight 
from a clinico-pathological study and a meta-analysis of 4241 cases. Atherosclerosis, Vol.202, No.2, (February 2009), pp.535-42, ISSN 0021-9150

García-Compeán, D., González González, JA., Marrufo García, CA., Flores Gutiérrez, JP., Barboza Quintana, O., Galindo Rodríguez, G., Mar Ruiz, MA., de León Valdez, D., Jaquez Quintana, JO. \& Maldonado Garza, HJ. (2011) Prevalence of eosinophilic esophagitis in patients with refractory gastroesophageal reflux disease symptoms: A prospective study. Digestive and Liver Diseases, Vol.43, No.3., (March 2011), pp.204-8, ISSN 1590-8658

Gąsiorowska, A. \& Fass R. (2008) The proton pump inhibitor (PPI) test in GERD: does it still have a role? Journal of Clinical Gastroenterology, Vol.42, No.8, (September 2008), pp.867-74, ISSN 0192-0790

Gąsiorowska, A., Navarro-Rodriguez, T., Dickman, R., Wendel, C., Moty, B., Powers, J., Willis, MR., Koenig, K., Ibuki, Y., Thai, H. \& Fass R. (2009) Clinical Trial: the Effect of Johrei on Symptoms of Patients with Functional Chest Pain (FCP)-A Pilot Study. Alimentary Pharmacology and Therapeutics, Vol.29, No.1, (January 2009), pp.126-34, ISSN 0269-2813

George, A. \& Movahed, A. (2010) Recognition of noncardiac findings on cardiac computed tomography examination. Reviews in Cardiovascular Medicine, Vol.11, No.2, (Spring 2010), pp.84-91, ISSN 1530-6550

Grundy, D., Al-Chaer, ED., Aziz, Q., Collins, SM., Ke, M., Taché, Y. \& Wood JD. (2006) Fundamentals of neurogastroenterology: basic science. Gastroenterology. Vol.130, No.5, (April 2006), pp.1391-411, ISSN 0016-5085

Hamer, M., Batty, GD., Seldenrijk, A. \& Kivimaki, M. (2011) Antidepressant medication use and future risk of cardiovascular disease: the Scottish Health Survey. European Heart Journal, Vol.32, No.4, (February 2011), ISSN 0195-668X

Hammett, RJ., Hansen, RD., Lorang, M., Bak, YT. \& Kellow JE. (2003) Esophageal dysmotility and acid sensitivity in patients with mitral valve prolapse and chest pain. Diseases of the Esophagus. Vol.16, No.2, (February 2003), pp.73-6, ISSN 11208694

Hebbard, G. (2010) Noncardiac chest pain: an unsatisfactory 'diagnosis'? Journal of Gastroenterology and Hepatology, Vol.25, No.12, (December 2010), pp.1811-2. ISSN:0815-9319

Hershcovici, T. \& Fass R. (2010) An algorithm for diagnosis and treatment of refractory GERD. Best Practice and Research. Clinical Gastroenterology, Vol.24, No.6, (December 2010), pp.923-36, ISSN 1521-6918

Hewson, EG., Dalton, CB., Hackshaw BT, Wu, WC. \& Richter JE. (1990) The prevalence of abnormal esophageal test results in patients with cardiovascular disease and unexplained chest pain. Archives of Internal Medicine, Vol.150, No.5, (May 1990), pp.965-9, ISSN 0003-9926

Hoff, DA., Gregersen, H., Odegaard, S., Liao, D. \& Hatlebakk, JG. (2010) Mechanosensation and mucosal blood perfusion in the esophagus of healthy volunteers studied with a multimodal device incorporating laser Doppler flowmetry and endosonography. Digestive Diseases and Sciences, Vol.55, No.2, (February 2009), pp.312-20, ISSN 01632116 
Hollander, JE., Robey, JL., Chase, MR., Brown, AM., Zogby, KE. \& Shofer FS. (2007) Relationship between a Clear-cut Alternative Noncardiac Diagnosis and 30-day Outcome in Emergency Department Patients with Chest Pain. Academic emergency medicine: official journal of the Society for Academic Emergency Medicine. Vol.14, No.3, (March 2007), pp.210-5, ISSN 1069-6563

Hsiao, FY., Tsai, YW., Huang, WF., Wen, YW., Chen, PF., Chang, PY. \& Kuo KN. (2009) A comparison of aspirin and clopidogrel with or without proton pump inhibitors for the secondary prevention of cardiovascular events in patients at high risk for gastrointestinal bleeding. Clinical Therapeutics, Vol.31, No.9, (September 2009), pp.2038-47, ISSN 0149-2918

Janssens, J., Vantrappen, G. \& Ghillebert G. (1986) 24-hour recording of esophageal pressure and $\mathrm{pH}$ in patients with noncardiac chest pain. Gastroenterology, Vol.90, No.6, (June 1986), pp.1978-84, ISSN 0016-5085

Jones, H., Cooper, P., Miller, V., Brooks, N. \& Whorwell PJ. (2006) Treatment of non-cardiac chest pain: a controlled trial of hypnotherapy. Gut, Vol.55, No.10, (October 2006), pp.1403-8, ISSN 0017-5749

Jou, CJ., Farber, JP., Qin, C. \& Foreman, RD. (2002) Convergent pathways for cardiac- and esophageal- somatic motor reflexes in rats. Autonomic neuroscience: basic and clinical., Vol.99, No.2, (August 2002), pp.70-7, ISSN 1566-0702

Juurlink, DN., Gomes, T., Ko, DT., Szmitko, PE., Austin, PC., Tu, JV., Henry, DA., Kopp, A. \& Mamdani, MM. (2009) A population-based study of the drug interaction between proton pump inhibitors and clopidogrel. CMAJ: Canadian Medical Association Journal. Vol.180, No.7, (January 2009), pp.713-8, ISSN 0820-3946

Kasprzak, M., Koziński, M., Bielis, L., Boińska, J., Plażuk, W., Marciniak, A., Budzyński, J., Siller-Matula, J., Rość, D. \& Kubica, J. (2009) Pantoprazole may enhance antiplatelet effect of enteric-coated aspirin in patients with acute coronary syndrome. Cardiology Journal, Vol.16, No.6, (June 2009), pp.535-544, ISSN 1897-5593

Katerndahl, D. (2004) Panic and Plaques: Panic Disorder and Coronary Artery Disease in Patients with Chest Pain J The Journal of the American Board of Family Practice, Vol.17, No.2, (March-April 2004), pp.114-26, ISSN 0893-8652

Kim, J., Henderson, RA., Pocock, SJ., Clayton, T., Sculpher, MJ., Fox, KA. \& RITA-3 Trial Investigators. (2005) Health-related quality of life after interventional or conservative strategy in patients with unstable angina or non-ST-segment elevation myocardial infarction: one-year results of the third Randomized Intervention Trial of unstable Angina RITA-3. Journal of the American College of Cardiology, Vol.45, No.2, (January 2005), pp.221-8, ISSN 0735-1097

Kłopocka M, Budzyński J, Świątkowski M, Augustyńska B. \& Pulkowski, G. (2006) Therapy with rabeprazole increases nitric oxide bioavailability. May it limit usefulness of empirical test with proton pump inhibitor in chest pain diagnosis? Medical and Biological Sciences, Vol.20, No.2, (January 2006), pp.57-61. ISSN 1734-591X

Kones, R. (2010) Recent advances in the management of chronic stable angina II. Antiischemic therapy, options for refractory angina, risk factor reduction, and revascularization. Vascular Health and Risk Management, Vol.6, (September 2010), pp.49-74, ISSN 1176-6344 
Konturek, PC., Celiński, K., Słomka, M., Cichoż-Lach, H., Burnat, G., Naegel, A., Bielański, W., Konturek, JW. \& Konturek, SJ. (2008) Melatonin and its precursor L-tryptophan prevent acute gastric mucosal damage induced by aspirin in humans. Journal of Physiology and Pharmacology, Vol.59, No.Suppl 2, (August 2008), pp.67-75, ISSN 0867-5910

Kowalski, M., Konturek, PC., Pieniążek, P., Karczewska, E., Kluczka, A., Grove, R., Kranig, W., Nasseri, R., Thale, J., Hahn, EG. \& Konturek, SJ. (2001) Prevalence of Helicobacter pylori infection in coronary artery disease and effect of its eradication on coronary lumen reduction after percutaneous coronary angioplasty. Digestive and Liver Diseases, Vol.33, No.3, (April 2001), pp.222-9, ISSN 1590-8658

Krysiak, W., Szabowski, S., Stepień, M., Krzywkowska, K., Krzywkowski, A. \& Marciniak P. (2008) Hiccups as a myocardial ischemia symptom. Polskie Archiwum Medycyny Wewnetrznej (Polish Archives of Internal Medicine), Vol.118, No.3, (March 2008), pp.148-51, ISSN 0032-3772

Kushnir, VM., Sayuk, GS. \& Gyawali, CP. (2010) Abnormal GERD parameters on ambulatory $\mathrm{pH}$ monitoring predict therapeutic success in noncardiac chest pain. The American Journal of Gastroenterolology, Vol.105, No.5, (November 2009), pp.10328, ISSN 0002-9270

Labenz, J. (2010) Facts and fantasies in extra-oesophageal symptoms in GORD. Best Practice and Research. Clinical Gastroenterology, Vol.24, No.6, (December 2010), pp.893-904, ISSN 1521-6918

Laheij, RJ., Van Rossum, LG., Krabbe, PF., Jansen, JB. \& Verheugt, FW. (2003) The impact of gastrointestinal symptoms on health status in patients with cardiovascular disease. Alimentary Pharmacology and Therapeutics, Vol.17, No.7, (April 2003), pp.881-5, ISSN 0269-2813

Laine, L. \& Hennekens, C. (2010) Proton pump inhibitor and clopidogrel interaction: fact or fiction? The American Journal of Gastroenterology, Vol.105, No.1, (January 2010), pp.34-41, ISSN 0002-9270

Laird, C, Driscoll, P. \& Wardrope, J. (2004) The ABC of community emergency care: chest pain. Emergency Medicine Journal, Vol.21, No.2, (March 2004), pp.226-32, ISSN 14720205

Lanza, GA, Grimaldi, R., Greco, S., Ghio, S., Sarullo, F., Zuin, G., De Luca, A., Allegri, M., Di Pede, F., Castagno, D., Turco, A., Sapio, M., Pinato, G., Cioni, B., Trevi, G. \& Crea F. (2011) Spinal cord stimulation for the treatment of refractory angina pectoris: a multicenter randomized single-blind study (the SCS-ITA trial). Pain, Vol.152, No.1, (January 2011), pp.45-52, ISSN 0304-3959

Leise, MD., Locke, GR 3rd., Dierkhising, RA., Zinsmeister, AR., Reeder, GS. \& Talley NJ. (2010) Patients dismissed from the hospital with a diagnosis of noncardiac chest pain: cardiac outcomes and health care utilization. Mayo Clinic Proceedings, Vol.85, No.4, (April 2010), pp.323-30, ISSN 0025-6196

Lemire, S. (1997) Assessment of clinical severity and investigation of uncomplicated gastroesophageal reflux disease and noncardiac angina-like chest pain. Canadian Journal Gastroenterology, Vol.11, Suppl B, (September 1997), pp.37B-40B, ISSN 08357900 
Lenfant, C. (2010) Chest pain of cardiac and noncardiac origin. Metabolism: clinical and experimental. Vol.59, Suppl 1, (October 2010), pp.S41-6, ISSN 0026-0495

Liuzzo, JP., Ambrose, JA. \& Diggs, P. (2005) Proton-pump inhibitor use by coronary artery disease patients is associated with fewer chest pain episodes, emergency department visits and hospitalizations. Alimentary Pharmacology and Therapeutics, Vol.22, No.2, (July 2005), pp.95-100, ISSN 0269-2813

McGillion, M., Cook, A., Victor, JC., Carroll, S., Weston, J., Teoh, K. \& Arthur HM. (2010) Effectiveness of percutaneous laser revascularization therapy for refractory angina. Vascular Health and Risk Management, Vol.6, (September 2010), pp.735-47, ISSN 11766344

Macpherson, H. \& Dumville, JC. (2007) Acupuncture as a potential treatment for noncardiac chest pain--a survey. Acupuncture in Medicine: Journal of the British Medical Acupuncture Society, Vol.25, No.1-2, (June 2007), pp.18-21, ISSN 0964-5284

Makk, LJ., Leesar, M., Joseph, A., Prince, CP. \& Wright RA. (2000) Cardioesophageal reflexes: an invasive human study. Digestive Diseases and Sciences, Vol.45, No.12, (December 2000), pp.2451-4, ISSN 0163-2116

Manfrini, O., Bazzocchi, G., Luati, A., Borghi, A., Monari, P. \& Bugiardini R. (2006) Coronary spasm reflects inputs from adjacent esophageal system. American Journal of Physiology. Heart and Circulatory Physiology, Vol.290, No.5, (May 2006), pp.H2085-91, ISSN 0363-6135

Mant, J., McManus, RJ., Oakes, RA., Delaney, BC., Barton, PM., Deeks, JJ., Hammersley, L., Davies, RC., Davies, MK. \& Hobbs, FD. (2004) Systematic review and modelling of the investigation of acute and chronic chest pain presenting in primary care. Health Technology Assessment, Vol.8, No.2, (February 2004), pp.1-158, ISSN 1366-5278

Marques, AH., Silverman, MN. \& Sternberg, EM. (2010) Evaluation of stress systems by applying noninvasive methodologies: measurements of neuroimmune biomarkers in the sweat, heart rate variability and salivary cortisol. Neuroimmunomodulation. Vol.17, No.3, (February 2010), pp.205-8, ISSN 1021-7401

Mayer, EA. \& Tillisch, K. (2011) The brain-gut axis in abdominal pain syndromes. Annual Review of Medicine, Vol.62, (February 2011), pp.381-96, ISSN 0066-4219

Mehta, AJ., de Caestecker, JS., Camm, AJ. \& Northfield, TC. (1996) Gastro-oesophageal reflux in patients with coronary artery disease: how common is it and does it matter? European Journal of Gastroenterology and Hepatology, Vol.8, No.10, (October 1996), pp.973-8, ISSN 0954-691X

Miyazaki, M., Babazono, A., Kadowaki, K., Kato, M., Takata, T. \& Une, H. (2006) Is Helicobacter pylori infection a risk factor for acute coronary syndromes? The Journal of Infection, Vol.52, No.2, (February 2006), pp.86-91, ISSN 0163-4453

Munk, EM., Nørgård, B., Dethlefsen, C., Gregersen, H., Drewes, AM., Funch-Jensen, P. \& Sørensen, HT. (2008) Unexplained chest/epigastric pain in patients with normal endoscopy as a predictor for ischemic heart disease and mortality: a Danish 10-year cohort study. BMC Gastroenterology, Vol.8, (July 2008), pp.28, ISSN 1471-230X

Nam, CW., Kim, KS., Lee, YS., Lee, SH., Han, SW., Hur, SH., Kim, YN., Kim, KB. \& Jang, BK. (2006) The incidence of gastro-esophageal disease for the patients with typical chest 
pain and a normal coronary angiogram. The Korean Journal of Internal Medicine, Vol.21, No.2, (June 2006), pp.94-6, ISSN 1226-3303

Nasr, I., Attaluri, A., Hashmi, S., Gregersen, H. \& Rao, SS. (2010) Investigation of esophageal sensation and biomechanical properties in functional chest pain. Neurogastroenterology and Motility: the official journal of the Gastrointestinal Motility Society, Vol.22, No.5, (May 2010), pp.520-6, e116, ISSN 1350-1925

Navarese, EP., Franceschi, F., Aurelio, A., Natale, L., Rebuzzi, AG. \& Gasbarrini, G. (2010) Focal myocarditis mimicking ST-elevation myocardial infarction in a patient with Helicobacter pylori infection: role of magnetic resonance with late gadolinium enhancement. Recenti progressi in medicina, Vol.101, No.2, (February 2010), pp.61-3, ISSN

Nema, H., Kato, M., Katsurada, T., Nozaki, Y., Yotsukura, A., Yoshida, I., Sato, K., Kawai, Y., Takagi, Y., Okusa, T., Takiguchi, S., Sakurai, M. \& Asaka, M. (2008) Endoscopic survey of low-dose-aspirin-induced gastroduodenal mucosal injuries in patients with ischemic heart disease. Journal of Gastroenterology and Hepatology, Vol.23, No.Suppl 2, (December 2008), pp.S234-6, ISSN 0815-9319

North, CS., Hong, BA. \& Alpers, DH. (2007) Relationship of functional gastrointestinal disorders and psychiatric disorders: implications for treatment. World Journal of Gastroenterology, Vol.13, No.14, (April 2007), pp.2020-7, ISSN 1007-9327

Numans, ME. \& de Wit, NJ. (2003) Reflux symptoms in general practice: diagnostic evaluation of the Carlsson-Dent gastro-oesophageal reflux disease questionnaire. Alimentary Pharmacology and Therapeutics,Vol.17, No.8, (April 2003), pp.1049-55, ISSN 0269-2813

Oranu, AC. \& Vaezi, MF. (2010) Noncardiac chest pain: gastroesophageal reflux disease. The Medical Clinics of North America, Vol.94, No.2, (March 2010), pp.233-42, ISSN 00257125

Palsson, OS. \& Whitehead, WE. (2006) Hypnosis for non-cardiac chest pain. Gut. Vol.55, No.10, (October 2006), pp.1381-4, ISSN 0017-5749

Patel, MR., Peterson, ED., Dai, D., Brennan, JM., Redberg, RF., Anderson, HV., Brindis, RG. \& Douglas, PS. (2010) Low diagnostic yield of elective coronary angiography. New England Journal Medicine, Vol.362, No.10, (March 2010), pp.886-95, ISSN 0028-4793

Pereira, Rde S. (2006) Regression of gastroesophageal reflux disease symptoms using dietary supplementation with melatonin, vitamins and aminoacids: comparison with omeprazole. Journal of Pineal Research Vol.41, No.3, (October 2006), pp.195-200, ISSN 0742-3098

Pfab, F., Winhard, M., Nowak-Machen, M., Napadow, V., Irnich, D., Pawlik, M., Bein, T. \& Hansen, E. (2011) Acupuncture in critically ill patients improves delayed gastric emptying: a randomized controlled trial. Anesthesia and Analgesia, Vol.112, No.1, (January 2011), pp.150-5, ISSN 0003-2999

Phan, A., Shufelt, C. \& Merz, CN. (2009) Persistent chest pain and no obstructive coronary artery disease. JAMA: the Journal of the American Medical Association, Vol.301, No.14, (April 2009), pp.1468-74, ISSN 0098-7484

Poole-Wilson, PA., Pocock, SJ., Fox, KA., Henderson, RA., Wheatley, DJ., Chamberlain, DA., Shaw, TR., Clayton, TC. \& Randomised Intervention Trial of unstable Angina 
Investigators. (2006) Interventional versus conservative treatment in acute non-ST elevation coronary syndrome: time course of patient management and disease events over one year in the RITA 3 trial. Heart, Vol.92, No.10, (October 2006), pp.1473-9, ISSN 1355-6037

Potts, SG. \& Bass, CM. (1995) Psychological morbidity in patients with chest pain and normal or near-normal coronary arteries: a long- term follow-up study. Psychological Medicine, Vol.25, No.2, (March 1995), pp.339-347, ISSN 0033-2917

Ramdeen, N, Aronow, WS., Chugh, S. \& Asija, A. (2008) Patients undergoing coronary angiography because of chest pain with hepatitis $C$ virus seropositivity have a higher prevalence of obstructive coronary artery disease than a control group. Archives of Medical Sciences, Vol.4, No.4, (December 2008), pp.452-454, ISSN 17341922

Rao, SS., Mudipalli, RS., Remes-Troche, JM., Utech, CL., Zimmerman, B. (2007) Theophylline improves esophageal chest pain- a randomized, placebo- controlled study. The American Journal of Gastroenterology, Vol.102, No.5, (May 2007), pp.930-8, ISSN 00029270

Rasmi, Y. \& Raeisi, S. (2009) Possible role of Helicobacter pylori infection via microvascular dysfunction in cardiac syndrome X. Cardiology Journal, Vol.16, No.6, (June 2009), pp.585-7, ISSN 1897-5593

Rasmussen, K., Funch-Jensen, P., Ravnsbaek, J., \& Bagger, J.P. (1986) Oesophageal spasm in patients with coronary artery spasm. Lancet, Vol.I, No.8474, (January 1986), pp.174176, ISSN 0140-6736

Remes-Troche, JM. (2010) The hypersensitive esophagus: pathophysiology, evaluation, and treatment options. Current Gastroenterology Reports, Vol.12, No.5, (October 2010), pp.417-26, ISSN 1522-8037

Ringstrom, E. \& Freedman, J. (2006) Approach to undifferentiated chest pain in the emergency department: a review of recent medical literature and published practice guidelines. The Mount Sinai Journal of Medicine, New York, Vol.73, No.2, (March 2006), pp.499-505, ISSN 0027-2507

Rosztóczy, A., Vass, A., Izbéki, F., Nemes, A., Rudas, L., Csanády, M., Lonovics, J., Forster, T. \& Wittmann, T. (2007) The evaluation of gastro-oesophageal reflux and oesophagocardiac reflex in patients with angina-like chest pain following cardiologic investigations. International Journal of Cardiology, Vol.118, No.1, (May 2007), pp.62-8, ISSN 0167-5273

Ruigómez, A., Massó-González, EL., Johansson, S., Wallander, MA. \& García-Rodríguez, LA. (2009) Chest pain without established ischaemic heart disease in primary care patients: associated comorbidities and mortality. The British Journal of General Practitioners: the Journal of the Royal College of general Practitioners, Vol.59, No.560, (March 2009), pp.e78-86, ISSN 0960-1643

Ruigómez, A., Rodríguez, LA., Wallander, MA., Johansson, S. \& Jones, R. (2006) Chest pain in general practice: incidence, comorbidity and mortality. Family Practice, Vol.23, No.2, (April 2006), pp.167-74, ISSN 0263-2136

Saleh, N., Svane, B., Jensen, J., Hansson, LO., Nordin, M. \& Tornvall, P. (2005) Stent implantation, but not pathogen burden, is associated with plasma C-reactive 
protein and interleukin-6 levels after percutaneous coronary intervention in patients with stable angina pectoris. American Heart Journal, Vol.149, No.5, (May 2005), pp.876-82, ISSN 0002-8703

Sandifer, QD., Vuilo, S. \& Crompton, G. (1996) Association of Helicobacter pylori infection with coronary heart disease. Association may not be causal. British Medical Journal, Vol.312, No.7025, (January 1996), pp.251, ISSN 0959-8138

Sarkar, S., Thompson, DG., Woolf, CJ., Hobson, AR., Millane, T. \& Aziz Q. (2004) Patients with chest pain and occult gastroesophageal reflux demonstrate visceral pain hypersensitivity which may be partially responsive to acid suppression. American Journal of Gastroenterology, Vol.99, No.10, (October 2004), pp.1998-2006, ISSN 00029270

Schofield, PM., Bennett, DH., Whorwell, PJ., Brooks, NH., Bray, CL., Ward, C. \& Jones, PE. (1987) Exertional gastro-oesophageal reflux: a mechanism for symptoms in patients with angina pectoris and normal coronary angiograms. British Medical Journal (Clin Res Ed), Vol.294, No.6585, (June 1987), pp.1459-61, ISSN 0267-0623

Schofield, PM., Whorwell, PJ., Brooks, NH., Bennett, DH. \& Jones PE. (1989) Oesophageal function in patients with angina pectoris: a comparison of patients with normal coronary angiograms and patients with coronary artery disease. Digestion, Vol.42, No.2, (February 1989), pp.70-8, ISSN 0012-2823

Seo, TH., Kim, JH., Lee, JH., Ko, SY., Hong, SN., Sung, IK., Park, HS. \& Shim, CS. (2010) Clinical distinct features of noncardiac chest pain in young patients. Journal of Neurogastroenterology and Motility, Vol.16, No.2, (April 2010), pp.166-71, ISSN 20930879

Shanker, J. \& Kakkar, VV. (2009) Role of Periodontal Infection in Cardiovascular Disease: a Current Perspective. Archives of Medical Sciences, Vol.5, No.2, (April 2009), pp.125134, ISSN 1734-1922

Sheps, DS., Creed, F. \& Clouse, RE. (2004) Chest pain in patients with cardiac and noncardiac disease. Psychosomatic Medicine. Vol.66, No.6, (November- December 2004), pp.861-7, ISSN 0033-3174

Sifrim, D. \& Blondeau, K. (2006) Technology insight: The role of impedance testing for esophageal disorders. Nature Clinical Practice. Gastroenterology and Hepatology, Vol.3, No.4, (April 2006), pp.210-9, ISSN 1743-4378

Sifrim, D., Blondeau, K. \& Mantillla, L. (2009) Utility of non-endoscopic investigations in the practical management of oesophageal disorders. Best Practice and Research. Clinical Gastroenterology, Vol.23, No.3, (March 2009), pp.369-86, ISSN 1521-6918

Sifrim, D., Mittal, R., Fass, R., Smout, A., Castell, D, Tack, J. \& Gregersen, H. (2007) Review article: acidity and volume of the refluxate in the genesis of gastro-oesophageal reflux disease symptoms. Alimentary Pharmacology and Therapeutics, Vol.25, No.9, (May 2007), pp.1003-17, ISSN 0269-2813

Singh, S., Richter, JE., Hewson, EG., Sinclair, JW. \& Hackshaw, BT. (1992) The contribution of gastroesophageal reflux to chest pain in patients with coronary artery disease. Annals of Internal Medicine, Vol.117, No.10, (November 1992), pp.824-30, ISSN 00034819 
Sorrentino, D., Bazzocchi, M., Badano, L., Toso, F. \& Giagu, P. (2005) Heart-touching Chilaiditi 's syndrome. World Journal of Gastroenterology, Vol.11, No.29, (August 2005), pp.4607-4609, ISSN 1007-9327

Stec, S., Tarnowski, W., Kalin, K., Sikora, K. \& Kołakowski P. (2010) High-resolution esophageal manometry with ECG monitoring for management of premature ventricular complexes-associated dysphagia. Dysphagia, Vol.25, No.1, (March 2010), pp.66-9, ISSN 0179-051X

Stöllberger, C. \& Finsterer, J. (2003) Treatment of esophagitis/vagitis-induced paroxysmal atrial fibrillation by proton-pump inhibitors. Journal of Gastroenterology, Vol.38, No.11, pp.1109, ISSN 0944-1174

Swap, CJ. \& Nagurney, JT. (2005) Value and limitations of chest pain history in the evaluation of patients with suspected acute coronary syndromes. JAMA: Journal of American Medical Association. Vol.294, No.20, (November 2005), pp.2623-9, ISSN 0098-7484

Świątkowski, M., Budzyński, J., Kłopocka, M., Pulkowski, G., Suppan, K., Fabisiak, J., Morawski, W. \& Majer M. (2004) Suppression of gastric acid production may improve the course of angina pectoris and the results of treadmill stress test in patients with coronary artery disease. Medical Science Monitor, Vol.10, No.9, (September 2004), pp.CR524-529, ISSN 1234-1010

Talaie, R., Forootan, M., Donboli, K., Dadashzadeh, N., Sadeghi, A., Poorsaadat, S., Moghimi, B., Alizadeh, AH. \& Zali MR. (2009) 24-hour ambulatory pH-metry in patients with refractory heartburn: a prospective study. Journal of Gastrointestinal and Liver Diseases, Vol.18, No.1, (March 2009), pp.11-5, ISSN 1841-8724

Thor, PJ. \& Błaut, U. (2006) Helicobacter pylori infection in pathogenesis of gastroesophageal reflux disease. Journal of Physiology and Pharmacology, Vol.57, Suppl 3, (September 2006), pp.81-90, ISSN 0867-5910

Tipnis, NA., Rhee, PL. \& Mittal, RK. (2007) Distension during gastroesophageal reflux: effects of acid inhibition and correlation with symptoms. American Journal of Physiology Gastrointestinal Liver Physiology, Vol.293, No.2, (August 2007), pp.G46974, ISSN 0193-1857

To, AC., Armstrong, G., Zeng, I. \& Webster MW. (2009) Noncardiac surgery and bleeding after percutaneous coronary intervention. Circulation. Cardiovascular Interventions, Vol.2, No.3, (April 2009), pp.213-21, ISSN 1941-7640

Tougas, G., Spaziani, R., Hollerbach, S., Djuric, V., Pang, C., Upton, AR., Fallen, EL. \& Kamath, MV. (2001) Cardiac autonomic function and oesophageal acid sensitivity in patients with non-cardiac chest pain. Gut Vol.49, No.5, (November 2001), pp.70612, ISSN 0017-5749

Upile, T., Jerjes, W., El Maaytah, M., Singh, S., Hopper, C. \& Mahil, J. (2006) Reversible atrial fibrillation secondary to a mega-oesophagus. BMC Ear Nose Throat Disord, Vol.6, No.15, (December 2006), pp.1-4, ISSN 1472-6815

Vakil, N., van Zanten, SV., Kahrilas, P., Dent, J., Jones, R. \& Global Consensus Group. (2006) The Montreal definition and classification of gastroesophageal reflux disease: a global evidence-based consensus. American Journal of Gastroenterology, Vol.101, No.8, (August 2006), pp.1900-20, ISSN 0002-9270 
Wang, WH., Huang, JQ., Zheng, GF., Wong, WM., Lam, SK., Karlberg, J., Xia, HH., Fass, R. \& Wong, BC. (2005) Is proton pump inhibitor testing an effective approach to diagnose gastroesophageal reflux disease in patients with noncardiac chest pain?: a meta-analysis. Archives of Internal Medicine, Vol.165, No.11, (June 2005), pp.1222-8, ISSN 0003-9926

Weigl, M., Gschwantler, M., Gatterer, E., Finsterer, J. \& Stöllberger, C. (2003) Reflux esophagitis in the pathogenesis of paroxysmal atrial fibrillation: results of a pilot study. Southern Medical Journal, Vol.96, No.11, (November 2003), pp.1128-32, ISSN $0038-4348$

Wood, JD. (2007) Neuropathophysiology of functional gastrointestinal disorders. World Journal of Gastroenterology, Vol.13, No.9, (March 2007), pp.1313-32, ISSN 1007-9327

Würtz, M., Grove, EL., Kristensen, SD. \& Hvas, AM. (2010) The Antiplatelet Effect of Aspirin is Reduced by Proton Pump Inhibitors in Patients With Coronary Artery Disease. Heart, Vol.96, No.5, (November 2009), pp.368-71, ISSN 1355-6037

Yin, J. \& Chen, JD. (2010) Gastrointestinal motility disorders and acupuncture. Autonomic Neuroscience: basic and clinical, Vol.157, No.(1-2), (October 2010), pp.31-7, ISSN 15660702

Zhang, CX., Qin, YM. \& Guo, BR. (2010) Clinical study on the treatment of gastroesophageal reflux by acupuncture. Chinese Journal of Integrated Medicine, Vol.16, No.4, (August 2010), pp.298-303, ISSN 1672-0415

Zhu, A., Kaneshiro, M. \& Kaunitz, JD. (2010) Evaluation and treatment of iron deficiency anemia: a gastroenterological perspective. Digestive Diseases and Science, Vol.55, No.3, (March 2010), pp.548-59, ISSN 0163-2116. 


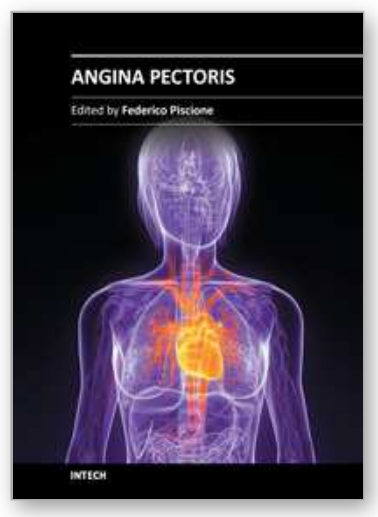

\author{
Angina Pectoris \\ Edited by Prof. Federico Piscione
}

ISBN 978-953-307-359-0

Hard cover, 184 pages

Publisher InTech

Published online 10, October, 2011

Published in print edition October, 2011

Angina is the most common disorder affecting patients with ischemic heart disease. This book provides a thorough review of fundamental principles of diagnosis, pathophysiology and treatment of angina pectoris, representing an invaluable resource not only for cardiologists, but also for general practitioners and medical students.

\title{
How to reference
}

In order to correctly reference this scholarly work, feel free to copy and paste the following:

Jacek Budzyński (2011). Angina-Like Chest Pain as a Symptom of Digestive Tract Disorders, Angina Pectoris, Prof. Federico Piscione (Ed.), ISBN: 978-953-307-359-0, InTech, Available from:

http://www.intechopen.com/books/angina-pectoris/angina-like-chest-pain-as-a-symptom-of-digestive-tractdisorders

\section{INTECH}

open science | open minds

\section{InTech Europe}

University Campus STeP Ri

Slavka Krautzeka 83/A

51000 Rijeka, Croatia

Phone: +385 (51) 770447

Fax: +385 (51) 686166

www.intechopen.com

\section{InTech China}

Unit 405, Office Block, Hotel Equatorial Shanghai

No.65, Yan An Road (West), Shanghai, 200040, China

中国上海市延安西路65号上海国际贵都大饭店办公楼 405 单元

Phone: +86-21-62489820

Fax: +86-21-62489821 
(C) 2011 The Author(s). Licensee IntechOpen. This is an open access article distributed under the terms of the Creative Commons Attribution 3.0 License, which permits unrestricted use, distribution, and reproduction in any medium, provided the original work is properly cited. 